NASA Technical Memorandum 106551

AIAA-94-3212

\title{
Use of Navier-Stokes Methods for the Calculation of High-Speed Nozzle Flow Fields
}

Nicholas J. Georgiadis and Dennis A. Yoder

Lewis Research Center

Cleveland, Ohio

Prepared for the

30th Joint Propulsion Conference cosponsored by the AIAA, ASME, SAE, and ASEE Indianapolis, Indiana, June 27-29, 1994

National Aeronautics and Space Administration 


\title{
USE OF NAVIER-STOKES METHODS FOR THE \\ CALCULATION OF HIGH-SPEED NOZZLE FLOW FIELDS
}

\author{
Nicholas J. Georgiadis* and Dennis A. Yoder \\ National Aeronautics and Space Administration \\ Lewis Research Center \\ Cleveland, Ohio
}

\begin{abstract}
$\underline{\text { Abstract }}$
Flows through three reference nozzles have been calculated to determine the capabilities and limitations of the widely used Navier-Stokes solver, PARC. The nozzles examined have similar dominant flow characteristics as those considered for supersonic transport programs. Flows from an inverted velocity profile (IVP) nozzle, an underexpanded nozzle, and an ejector nozzle were examined. PARC calculations were obtained with its standard algebraic turbulence model, Thomas, and the two-equation turbulence model, Chien k- $\varepsilon$. The Thomas model was run with the default coefficient of mixing set both at 0.09 and a larger value of 0.13 to improve the mixing prediction. Calculations using the default value substantially underpredicted the mixing for all three flows. The calculations obtained with the higher mixing coefficient better predicted mixing in the IVP and underexpanded nozzle flows but adversely affected PARC's convergence characteristics for the IVP nozzle case. The ejector nozzle case did not converge with the Thomas model and the higher mixing coefficient. The Chien $k-\varepsilon$ results were in better agreement with the experimental data overall than were those of the Thomas run with the default mixing coefficient, but the default boundary conditions for $\mathrm{k}$ and $\varepsilon$ underestimated the levels of mixing near the nozzle exits.
\end{abstract}

\section{Nomenclature}

A cross-sectional area in ejector nozzle mixing region

$\mathrm{A}^{+} \quad$ van Driest damping constant $=26$

$\mathrm{C}_{\varepsilon 1} \quad$ Chien $\mathrm{k}-\varepsilon$ turbulence model constant $=1.35$

$\mathrm{C}_{\varepsilon 2}$ Chien $\mathrm{k}-\varepsilon$ turbulence model constant $=1.8$

$\mathrm{C}_{\mu} \quad$ Chien $\mathrm{k}-\varepsilon$ turbulence model constant $=0.09$

$\mathrm{f}_{\mu}, \mathrm{f}_{1}, \mathrm{f}_{2}$ terms in Chien $\mathrm{k}-\varepsilon$ turbulence model

$\mathrm{H}$ distance from centerline to top or bottom wall of ejector nozzle

K Von Karman constant $=0.41$

$\mathrm{k} \quad$ turbulent kinetic energy

$\ell \quad$ turbulent mixing length

$\ell \quad$ Thomas model constant (default value $=0.09$ )

$\mathrm{Re}_{\mathrm{t}} \quad$ Reynolds number based on turbulent quantities

$\mathrm{t}$ time

*Member AIAA

$\begin{array}{ll}u, v & \text { velocities } \\ x, y & \text { cartesian coordinates } \\ y^{+} & \text {vertical distance normalized with shear length scale } \\ \beta & \text { ejector nozzle mixing parameter } \\ \varepsilon & \text { rate of turbulent kinetic energy dissipation } \\ \mu & \text { dynamic viscosity } \\ \mu_{t} & \text { turbulent viscosity } \\ \Pi & \text { production term in Chien } k-\varepsilon \text { model } \\ \rho & \text { density } \\ \sigma_{k} & \text { Chien } k-\varepsilon \text { turbulence model constant }=1.0 \\ \sigma_{\varepsilon} & \text { Chien } k-\varepsilon \text { turbulence model constant }=1.3 \\ \omega & \text { vorticity } \\ \omega_{c} & \text { Thomas model maximum vorticity }\end{array}$

Subscripts:

$i, j \quad$ computational coordinates

$\max$ maximum

min minimum

\section{Introduction}

In the High-Speed Research (HSR) program, NASA and industry are using computational fluid dynamics (CFD) codes to analyze flow fields from low-noise nozzle concepts that could be installed on a High-Speed Civil Transport (HSCT). Supersonic transport development programs of previous decades, such as the supersonic transport (SST) program, ${ }^{1}$ relied almost exclusively upon wind tunnel tests to evaluate propulsion system components. Recent advances in computer technology and flow-solving methods have made CFD codes a useful complement to wind tunnel tests.

CFD has been successfully employed to predict the internal flow quantities such as thrust coefficients, discharge coefficients, and pressure distributions, but only for nozzles with simple geometries, which produce single streams with no regions of separations. ${ }^{2-4}$ Nozzle flows involving the mixing of a primary stream with lower energy secondary streams are much more difficult to calculate. These flows are, however, characteristic of those considered for HSCT application. The mixer-ejector nozzles of the current HSR program, for example, are designed to entrain ambient air that mixes with the high-energy core flow. The reduced maximum velocities and temperatures of the mixed flow at the nozzle exit plane produce less noise than an unmixed 
nozzle. Recent applications of Full Navier-Stokes (FNS) analysis to such mixer-ejector nozzles are presented in Refs. 5 and 6 .

Because FNS codes are now being relied upon to analyze complex HSR nozzles, it is important to determine the capabilities of currently available codes and to identify aspects that require improvement. As a step in this direction, the multipurpose FNS solver PARC is applied to the following three reference nozzle flows: (1) an inverted velocity profile nozzle, (2) an underexpanded nozzle with the jet exiting into Mach 0.6 external flow, and (3) an ejector nozzle. These three cases each involve the mixing of a highenergy nozzle stream with a secondary stream (or streams) of lower energy, and are characteristic of nozzles currently considered for use in the HSR program or previously considered in past supersonic transport programs. They provide data sets appropriate for evaluating the capability of codes like PARC to predict quantities indicative of mixing (velocities and temperatures). These cases, however, require significantly less grid generation effort and CPU time to obtain a converged solution than the actual nozzles being considered in the HSR program (such as those described in Refs. 5 and 6).

The following discussion begins with a brief description of the code used in this study, PARC. Then, for each of the three test cases, the experimental background is presented followed by a description of the procedure employed to obtain calculations and the comparison with experimental data. Effects of turbulence model selection on flow field predictions are emphasized in the discussion.

\section{The PARC Code}

The PARC code ${ }^{7,8}$ is an internal flow Navier-Stokes code used extensively by government and industry to analyze propulsion flows. PARC was derived from the ARC external flow Navier-Stokes code. ${ }^{9,10}$ One version of the PARC code contains the two-dimensional and axisymmetric solver (PARC2D), whereas the other version contains the threedimensional solver (PARC3D). The governing equations of motion are the time-dependent, Reynolds-averaged NavierStokes equations satisfying a perfect gas relationship and Fourier's heat conduction law. These equations are expressed in conservation law form with respect to general curvilinear coordinates and are solved with the Beam and Warming approximate factorization algorithm. ${ }^{11}$ A timedependent solver based on a multistage algorithm of Jameson has been incorporated into PARC. ${ }^{12}$ PARC, however, is generally used for steady-state flow simulations.

Both algebraic and two-equation turbulence models are currently available in PARC to analyze turbulent flows. The standard algebraic turbulence model is based on the work of P.D. Thomas. ${ }^{13}$ This model calculates turbulent viscosity near surfaces (wall-bounded part of the model) and in regions where two or more flows are mixing (free-shear layer part of the model) but was optimized for the latter. The Baldwin-Lomax algebraic turbulence model $^{14}$ is also available in PARC. Baldwin-Lomax only calculates turbulent viscosity in wall-bounded regions.

Algebraic turbulence models often model complex flow cases inadequately because the single mixing length distributions used to calculate turbulent viscosity are normally tuned to a particular case and are not applicable to all flows. Two-equation models avoid this single mixing length limitation by solving two additional transport equations to calculate turbulent viscosity, but they are more computationally expensive. The Chien low Reynolds number $\mathrm{k}-\varepsilon$ model $^{15}$ with modifications for compressibility added by Nichols ${ }^{16}$ is available in the two-dimensional, axisymmetric code (PARC2D).

Two turbulence models were used with PARC2D in this nozzle study to obtain calculations for the three flow cases: the Thomas model (the default algebraic turbulence model) and the Chien $\mathrm{k}-\varepsilon$ model. The details of these two models are presented next.

\section{Turbulence Models in PARC}

\section{Thomas Model}

The Thomas algebraic turbulence model installed in PARC uses Prandtl's mixing length hypothesis to calculate turbulent viscosity

$$
\mu_{\mathrm{t}}=\rho \ell^{2}|\omega|
$$

The turbulent viscosities for wall-bounded regions and unbounded regions are calculated separately, based on the length scale distributions. For wall-bounded regions the turbulent mixing length is described as

$$
\ell=K y\left(1-\mathrm{e}^{-\mathrm{y}^{+} / \mathrm{A}^{+}}\right)
$$

For unbounded regions the turbulent mixing length is

$$
\ell=\frac{\ell_{0}\left[\max \left(\left|u_{j}\right|\right)-\min \left(\left|u_{j}\right|\right)\right]}{\omega_{c}}
$$

where $\ell_{\mathrm{o}}$ is an adjustable constant that is input as the variable COFMIX in the PARC code. The default value of COFMIX is 0.09. Because previous flow simulations using the Thomas model with $\ell_{0}=0.09$ have underpredicted the extent of mixing, ${ }^{17}$ the three nozzle cases of this study were examined by using the Thomas model with $\ell_{0}=0.13$ in addition to the default value. This larger value of $\ell_{0}$ was selected because it provides twice the turbulent viscosity for a given density and vorticity field. 


\section{Chien $k-\varepsilon$ Model}

The low Reynolds number $\mathrm{k}-\varepsilon$ model of Chien solves for the turbulent viscosity $\left(\mu_{t}\right)$ as a function of turbulent kinetic energy $(k)$ and rate of turbulent kinetic energy dissipation $(\varepsilon)$ as follows:

$$
\mu_{t}=C_{\mu} f_{\mu} \rho k^{2} / \varepsilon
$$

The quantities $\mathrm{k}$ and $\varepsilon$ are solved from the two transport equations

$$
\frac{D(\rho k)}{D t}=\frac{\partial}{\partial x_{i}}\left[\left(\mu+\frac{\mu_{t}}{\sigma_{k}}\right) \frac{\partial k}{\partial x_{i}}\right]+\Pi-\rho \varepsilon-\frac{2 \mu k}{y^{2}}
$$

and

$$
\begin{array}{r}
\frac{D(\rho \varepsilon)}{D t}=\frac{\partial}{\partial x_{i}}\left[\left(\mu+\frac{\mu_{t}}{\sigma_{\varepsilon}}\right) \frac{\partial \varepsilon}{\partial x_{i}}\right]+C_{\varepsilon 1} f_{1} \Pi \frac{\varepsilon}{k} \\
-C_{\varepsilon 2} f_{2} \rho \frac{\varepsilon^{2}}{k}-2 \mu \frac{\varepsilon}{y^{2}} e^{\left(-0.5 y^{+}\right)}
\end{array}
$$

with

$$
\Pi=\mu_{t} \frac{\partial u_{j}}{\partial x_{i}}\left(\frac{\partial u_{j}}{\partial x_{i}}+\frac{\partial u_{i}}{\partial x_{j}}\right)
$$

and

$$
\begin{gathered}
f_{\mu}=1-e^{\left(-0.0115 y^{+}\right)} \\
f_{1}=1.0 \\
f_{2}=1.0-0.22 e^{-(\operatorname{Re} / \sigma)^{2}} \\
\operatorname{Re}_{t}=\frac{\rho k^{2}}{\mu \varepsilon}
\end{gathered}
$$

\section{Discussion of Flow Cases}

Three PARC calculations were run for each of the test cases described in following sections. The first used the Thomas model with the default $\ell_{0}=0.09$, and the second used Thomas with $\ell_{0}=0.13$. These will be referred to as Thomas (0.09) and Thomas (0.13) in the rest of this discussion. The third calculation used the Chien $\mathrm{k}-\varepsilon$ model.

\section{Inverted Velocity Profile Nozzle}

One of the major environmental challenges NASA and industry are addressing in the HSR program is controlling the jet noise that will be produced by the HSCT's high thrust engines. ${ }^{18,19}$ One concept that has been examined extensively is the inverted velocity profile (IVP) nozzle. IVP nozzles maintain an outer nozzle flow at a higher velocity than the inner nozzle flow. They have been shown to reduce noise relative to a reference conical nozzle. ${ }^{20,21}$

In the current study, an IVP nozzle tested by von Glahn ${ }^{22,23}$ was investigated with PARC. Figure 1 is a schematic of the geometry, and Fig. 2 shows the computational grid near the nozzle exit plane. The grid was packed to the walls in the vertical direction to resolve the developing boundary layers, and it was packed to the exit plane in the horizontal direction to resolve the sharp gradients of the interacting flows. The dark portions of Fig. 2 indicate the locations of high grid density. Because the flow was axisymmetric, the bottom grid line is the axis of symmetry. The grid had 251 horizontal points and 191 vertical points, and it extended $1000 \mathrm{~cm}$ downstream of the nozzle exit plane (approximately 100 inner nozzle diameters) and $90 \mathrm{~cm}$ above the axis of symmetry.

The flow case investigated with PARC had a primary outer flow operating at a total temperature of $1125 \mathrm{~K}$ and Mach 0.67 and a secondary inner flow operating at a total temperature of $290 \mathrm{~K}$ and Mach 1.00 , as measured at the nozzle exit plane. The outer flow exited the nozzle at a higher velocity, but lower Mach number, than the inner flow because of its much higher temperature. The surrounding air was at rest. The inflow conditions for PARC were constructed by using one-dimensional isentropic relations to determine the total conditions that would provide the velocities and temperatures measured in the experiment near the exit plane. This was done because upstream experimental conditions were not specified. ${ }^{22,23}$ Typically, nozzle total pressures and temperatures are specified at the inflow for PARC calculations. Because PARC has difficulty in converging flows at low speeds (or still air, as in this case), the free stream was modeled as having a forward velocity.

Several difficulties were encountered in the initial attempts to obtain solutions for this IVP nozzle case. First, the packing of the initial grid was too sparse at the nozzle exit plane. Increasing the grid density to that shown in Fig. 2 helped resolve the sharp flow gradients between the nozzle flows and the ambient air. Second, the external flow separated from the aft-facing surface. Moving the free-stream inflow boundary to the nozzle exit plane eliminated the area of separation and assisted convergence. Finally, because the surrounding air in the experiment was at rest, it was desirable to run the PARC calculations with as low a free-stream Mach number as possible. The initial calculations were run with a free-stream Mach number of 0.60 . This was gradually reduced to the lowest Mach number that provided converged solutions for all three PARC calculations, 0.45 .

Velocity profiles obtained from the PARC calculations are compared to experimental data in Fig. 3. At a location $20 \mathrm{~cm}$ downstream of the nozzle exit (Fig. 3a), the maximum velocities of the inner flow (from the axis of symmetry to a radial position of approximately $5 \mathrm{~cm}$ ) and the outer flow 
(from $5 \mathrm{~cm}$ to approximately $8 \mathrm{~cm}$ ) match the data well. This indicates that the nozzle inflow boundary conditions were calculated accurately. Further downstream, at $40 \mathrm{~cm}$ (Fig. 3b), $81 \mathrm{~cm}$ (Fig. 3c), and $130 \mathrm{~cm}$ (Fig. 3d), none of the three PARC solutions show a flow decay as rapid as the experimental data. The Thomas (0.09) solution shows the least decay at $81 \mathrm{~cm}$ and $130 \mathrm{~cm}$ downstream of the nozzle exit. The static temperature comparisons in Fig. 4 demonstrate the same trends. At $130 \mathrm{~cm}$ downstream (Fig. 4d), the Chien $\mathrm{k}-\varepsilon$ solution shows more temperature decay than the other flow solutions but still substantially less than the experimental data.

Although the inability of the three PARC calculations to produce the same flow decay as the experimental data was largely due to the presence of the Mach 0.45 free-stream flow in the calculations, the differences among the solutions were due to the significantly different turbulent viscosity levels that were calculated for each case. Figure 5 shows turbulent viscosity contours $\left(\mu_{\mathrm{r}} / \mu\right)$ for the three PARC solutions. The Thomas (0.09) solution (Fig. 5a) calculated less turbulent viscosity than the other two solutions throughout the flow field, which resulted in the poorest velocity and temperature decay characteristics. The Thomas $(0.13)$ solution (Fig. 5b) shows higher levels of turbulent viscosity than the Thomas (0.09) solution, but its contours are discontinuous. The Thomas $(0.13)$ solution was the only one of the three that remained somewhat oscillatory and had some difficulty in converging.

Because the Chien $\mathrm{k}-\varepsilon$ model calculates turbulent viscosity by solving transport equations, boundary conditions for $\mathrm{k}$ and $\varepsilon$ must be specified at each of the boundaries, including the inflow. The quantities $\mathrm{k}$ and $\varepsilon$ were not measured in the experiment, so the default boundary conditions for the inflow, extrapolations of the values for $\mathrm{k}$ and $\varepsilon$ from the interior, were used. Equation (4) shows that the calculated turbulent viscosity is proportional to $\mathrm{k}^{2}$. Near the inflow boundary, the values of $\mathrm{k}$ were quite small, and as a result, the Chien $\mathrm{k}-\varepsilon$ solution's turbulent viscosity contours (Fig. 5c) are quite low just downstream of the nozzle exit (as low or lower than the two Thomas solutions) but much higher further downstream.

\section{Underexpanded Nozzle}

The second flow case investigated was the underexpanded nozzle tested by Heltsley and Crosswy. ${ }^{24}$ Unlike the IVP nozzle, the underexpanded nozzle was tested in a wind tunnel operating at a Mach number of 0.6 ; therefore, the freestream Mach number for the PARC calculations was not specified artificially. A schematic of this axisymmetric single flow nozzle is shown in Fig. 6. The grid near the nozzle exit plane is shown in Fig. 7. The internal surface of the nozzle upstream of the throat was modified by removing a sharp corner to simplify grid generation. This grid had 251 horizontal points and 141 vertical points, and it extended
$60.96 \mathrm{~cm}$ in the horizontal direction from the nozzle exit plane and $15.24 \mathrm{~cm}$ in the vertical direction from the axis of symmetry (bottom grid line). The flow case investigated had the following operating conditions: a wind tunnel stagnation pressure of $136.4 \mathrm{kPa}$, a free-stream Mach number of 0.60 , a free-stream stagnation temperature of $355.5 \mathrm{~K}$, a nozzle Mach number of 1.563 at the exit plane, a nozzle stagnation temperature of $355.5 \mathrm{~K}$, and a nozzle static pressure ratio (static pressure of the flow at the nozzle exit plane divided by the free-stream static pressure) of 4.5. The three PARC calculations obtained for this nozzle flow converged relatively easily and did not demonstrate the grid or free-stream difficulties that the IVP nozzle presented.

The experimental data indicates that a normal shock occurs near $x=2.50 \mathrm{~cm}$. All of the PARC calculations predicted the shock to occur at approximately $2.30 \mathrm{~cm}$ downstream of the nozzle exit, and thus they are in good agreement with the experimental data. Adamson and Nicholls ${ }^{25}$ presented data that indicate an underexpanded nozzle operating under similar conditions but exiting into still air has a normal shock occurring at approximately $2.00 \mathrm{~cm}$ downstream of the nozzle exit.

Figure 8 shows velocity profiles at four stations downstream of the nozzle exit. At $1.27 \mathrm{~cm}$ downstream of the nozzle exit (Fig. 8a), the velocities are much higher than the experimental data. The large difference at this location may be due in part to aluminum oxide particles, as measured by laser Doppler velocimetry (LDV), lagging in velocity relative to the highly accelerating flow leaving the nozzle. Further downstream, the solutions vary widely. Good agreement with experimental data is achieved only with the Thomas (0.013) solution at $6.35 \mathrm{~cm}$ (Fig. 8c) and $8.90 \mathrm{~cm}$ (Fig. 8d) downstream. The Thomas (0.09) and Chien k- $\varepsilon$ solutions demonstrate significantly less core flow decay.

The differences in these velocity profiles relative to the experimental data are due to the variation in turbulent viscosities calculated in the flows. Turbulent viscosity contours are shown in Fig. 9. The Thomas (0.13) solution (Fig. 9b) has turbulent viscosity levels that are much higher just downstream of the nozzle exit. The Chien $k-\varepsilon$ turbulent viscosity levels (Fig. 9c) do not become substantially higher than the Thomas (0.09) levels (Fig. 9a) until well downstream of the last position where experimental velocities were available for comparison $(x=8.90 \mathrm{~cm})$. As for the IVP nozzle case, the Chien $\mathrm{k}-\varepsilon$ calculation used the default inflow boundary conditions with the turbulent quantities extrapolated from the interior. Using more accurate values for $\mathrm{k}$ and $\varepsilon$ at the inflow may have improved the agreement with experimental data.

\section{Ejector Nozzle}

The last test case examined was a two-dimensional ejector nozzle, which is a simplification of the mixer-ejector nozzles 
considered in the HSR program. Mixer-ejector nozzles ${ }^{26}$ entrain large amounts of secondary air that mix with the high energy flow from the engine core to lower the average jet velocity and resultant jet noise. High thrust levels are maintained despite the lower average jet velocity due to the mass augmentation of the secondary airflow. Mixer-ejector nozzles are a specific class of ejector nozzles that utilize devices such as lobed chutes to enhance mixing.

Ejector nozzles have received much attention for their potential application in providing thrust augmentation for vertical and short takeoff or landing (VSTOL) aircraft. Bevilaqua discusses some of the fundamentals of ejector nozzle operation and performance in Refs. 27 and 28. Analyses of ejector nozzle concepts began with, and continues to include, theoretical treatments. In recent years, CFD has also been applied to ejector nozzle concepts. $5,6,29$

For the current study, a two-dimensional ejector nozzle tested by Gilbert and Hill ${ }^{30}$ was investigated with PARC. Figure 10 shows the geometry of the ejector test rig used in their experiments. The flow case that was investigated with PARC is referred to as run number 9 in Ref. 30. This flow case had the following operating conditions: a primary nozzle total pressure of $246 \mathrm{kPa}$, a primary total temperature of $358 \mathrm{~K}$, an ambient pressure of $101 \mathrm{kPa}$, and an ambient temperature of $305 \mathrm{~K}$. Figure 11 shows the details of the computational grid used in the PARC calculations in the vicinity of the primary nozzle and secondary flow inlet. The upstream portion of the secondary flow inlet was modeled as shown in Fig. 10 to avoid grid skewness problems that would have occurred with exactly modeling the ejector wall far upstream. The grid had 251 horizontal and 121 vertical grid points, and it extended to $26.7 \mathrm{~cm}$ downstream of the nozzle exit plane (immediately before the diffuser entrance). The $\mathrm{x}$-axis is a line of symmetry, and positions in the mixing section are measured relative to the primary nozzle exit plane $(\mathrm{x}=0 \mathrm{~cm})$.

In obtaining calculations with PARC, only the Thomas (0.09) and Chien $k-\varepsilon$ models provided converged solutions. The Thomas ( 0.13 ) calculation's large, but discontinuous, turbulent viscosities caused sporadic mixing through the ejector nozzle that was not compatible with the free boundary condition at the outflow (pressure and temperature are specified). The Thomas (0.13) model calculated turbulent viscosities that were discontinuous for the IVP and underexpanded nozzles, but for those cases, the free boundary condition was specified far downstream and did not conflict with the mixing flows. As a result, only the Thomas (0.09) and Chien $\mathrm{k}-\varepsilon$ solutions are compared for this ejector nozzle case.

Figure 12 shows velocity profiles at four stations in the mixing section. The PARC calculations were obtained for only half of the test section because of symmetry. The experimental data, obtained for the entire height of the test section, showed some asymmetry which may be observed in Fig. 12, particularly near the mixing region centerline. For each axial station, the velocity profiles are plotted versus normalized vertical position $(y / H)$, where $H$ is the local distance from the centerline to either the top wall or bottom wall. These velocity profiles show that the Chien $k-\varepsilon$ solution matches the experimental velocity profiles much more closely than the Thomas (0.09) solution. The Chien $k-\varepsilon$ solution shows that the mixing close to the nozzle exit is underpredicted somewhat, which again may be due to the inflow boundary conditions used for $\mathrm{k}-\varepsilon$. The agreement with experimental data improves further downstream of the nozzle exit.

A measure of mixing effectiveness proposed by Bevilaqua $^{28}$ relates the mixing effectiveness $(\beta)$ to the flatness of the velocity profile:

$$
\beta=\frac{\int v^{2} d A}{\bar{v}^{2} A}
$$

This parameter was calculated for the PARC solutions and the experimental data. Figure 13 compares the mixing effectiveness obtained from the PARC calculations using both turbulence models with the experimental data and shows that the Chien $k-\varepsilon$ solution agrees best with the experimental data. Figure 14 shows total temperature profiles at two positions in the mixing section. Neither solution predicts the correct decay of the temperature in the center of the flow. Throughout the mixing section, the $\mathrm{k}-\varepsilon$ solution agrees much better with the experimental data than does the Thomas (0.09) solution.

Figure 15 shows turbulent viscosity contours for the Thomas (0.09) and Chien $\mathrm{k}-\varepsilon$ solutions. The Chien $\mathrm{k}-\varepsilon$ model's much higher levels of turbulent viscosity are directly responsible for better mixing predictions relative to the Thomas (0.09) calculation. Although the Chien $k-\varepsilon$ model predicted the mixing behavior quite well, the agreement with experimental data possibly could have been improved if more appropriate boundary conditions for $\mathrm{k}$ and $\varepsilon$ were used at the inflow.

A final comparison of the solutions to experimental data is provided in terms of predicted mass flow. Since mass augmenting ejectors have been designed to entrain as much secondary flow as possible, the pumping ratio (defined as the ratio of entrained secondary mass flow to primary mass flow) has been used as a measure of ejector effectiveness. In the Gilbert and Hill experiment, the pumping ratio was 4.67 , whereas the PARC solution using the Chien $\mathrm{k}-\varepsilon$ model provided a pumping ratio of 4.28 and that using Thomas (0.09) predicted 4.17. The CFD results indicate that the secondary flow entrainment is relatively independent of the extent of mixing. 


\section{Conclusions}

Navier-Stokes calculations have been compared to experimental data for three reference nozzles that have many of the same dominant flow characteristics as those considered for supersonic transport application. The calculations were obtained with the general purpose Navier-Stokes solver PARC, using the code's standard Thomas algebraic turbulence model (with the default coefficient of mixing, $\ell_{0}=$ 0.09 , and a larger value, $\ell_{0}=0.13$, in an attempt to improve mixing in the calculations) and the Chien two-equation $\mathrm{k}-\varepsilon$ model.

The solutions obtained with Thomas (0.09) substantially underpredicted the extent of mixing for all three flows. Those obtained with Thomas $(0.13)$ provided better results for the IVP nozzle and underexpanded nozzle flows relative to those obtained with Thomas (0.09), but the larger magnitudes of turbulent viscosity also caused the calculations to have poorer convergence characteristics for the IVP nozzle case. For the ejector nozzle flow, the Thomas $(0.13)$ calculation did not converge. Well downstream of the nozzle exit, the Chien $\mathrm{k}-\varepsilon$ model produced somewhat better mixing characteristics for the IVP nozzle than did the Thomas (0.09), and it agreed much more closely with experimental data for the ejector nozzle case. The Chien $\mathrm{k}-\varepsilon$ solution did not provide better agreement with experimental data than the Thomas solutions did for the underexpanded nozzle flow. However, the velocities obtained with LDV were only available for axial positions very close to the nozzle exit, and it was determined that the inflow boundary conditions used for $\mathrm{k}$ and $\varepsilon$ resulted in low levels of turbulent mixing close to the nozzle exits of the three cases examined.

The results of this study indicate that the selection of turbulence model has a significant effect on the calculation of high-speed nozzle flows. The Thomas model using $\ell_{0}=$ 0.09 (which was intended for free shear layer calculations) appears to be inadequate for the calculation of nozzle flows such as those considered here. Using $\ell_{0}=0.13$ improved the level of mixing for the unbounded free shear layer flows but adversely affected PARC's convergence characteristics. The Chien $\mathrm{k}-\varepsilon$ model produces better flow field predictions overall than Thomas $(0.09)$ but its default inflow boundary conditions for $\mathrm{k}$ and $\varepsilon$ caused an underestimation of mixing near the nozzle exit. Using more appropriate boundary conditions may help solve this problem.

Improving the capabilities of Navier-Stokes codes such as PARC to calculate complex nozzle flows will require continued development and implementation of appropriate turbulence models (and boundary conditions for turbulence models that solve transport equations like $\mathrm{k}-\varepsilon$ ). In addition, the ability of compressible flow codes to handle static or very slow flow conditions (like the air surrounding the IVP nozzle) must be improved. The nozzle test cases examined in this study can be used to show where progress is being made in these areas and to what extent Navier-Stokes solvers can be expected to provide reliable nozzle flow predictions.

\section{$\underline{\text { References }}$}

1. Stitt, Leonard E., "Exhaust Nozzles for Propulsion Systems With Emphasis on Supersonic Cruise Aircraft," NASA RP-1235, 1990.

2. Lai, H., and Nelson, E., "Comparison of 3D Computation and Experiment for Non-Axisymmetic Nozzles," AIAA Paper 89-0007, January 1989.

3. Carlson, J.R., and Abdol-Hamid, K.S., "Prediction of Internal Performance for Two-Dimensional ConvergentDivergent Nozzles," AIAA Paper 91-2369, June 1990.

4. Carlson, J.R., "A Nozzle Internal Performance Prediction Method," NASA TP-3221, 1992.

5. Malecki, R., Mityas, S., and Lord, W., "Navier-Stokes Analysis of an Ejector and Mixer-Ejector Operating at Pressure Ratios in the Range 2-4," AIAA Paper 90-2730, July 1990.

6. DeBonis, J.R., "Full Navier-Stokes Analysis of a TwoDimensional Mixer/Ejector Nozzle for Noise Suppression," AIAA Paper 92-3570, July 1992.

7. Cooper, G.K., and Sirbaugh, J.R., "The PARC Distinction: A Practical Flow Simulator," AIAA Paper 902002, July 1990.

8. Cooper, G.K., and Sirbaugh, J.R., "PARC Code: Theory and Usage," Arnold Engineering Development Center Report AEDC-TR-89-15, December 1989.

9. Pulliam, T.H., "Euler and Thin Layer Navier-Stokes Codes: ARC2D, ARC3D.,"Notes for Computational Fluid Dynamics User's Workshop, The University of Tennessee Space Institute, Tullahoma, Tennessee, (UTSI Publication E02-4005-023-84), 1984, pp. 15.1-15.85.

10. Pulliam, T.H., and Steger, J.L., "Implicit Finite Difference Simulations of Three Dimensional Compressible Flow," AIAA Journal, Vol. 18., No. 2, February 1980, pp. 159-167.

11. Beam, R.M., and Warming, R.F., "An Implicit FiniteDifference Algorithm for Hyperbolic Systems in Conservation-Law Form-Application to Eulerian Gasdynamic Equations," Journal of Computational Physics, Vol. 22, No. 1, 1976, pp. 87-110. 
12. Jameson, A., Schmidt, W., and Turkel, E., "Numerical Solutions of the Euler Equations by Finite Volume Method for Solving the Euler and Navier-Stokes Equations for High Speed Flows," AIAA Paper 81-1259, June, 1981.

13. Thomas, P.D., "Numerical Method for Predicting Flow Characteristics and Performance of Nonaxisymmetric Nozzles, Theory;" NASA CR-3147, 1979.

14. Baldwin, B.S., and Lomax, H., "Thin Layer Approximation and Algebraic Model for Separated Turbulent Flows," AIAA 78-257, January 1978.

15. Chien, K.-Y., "Predictions of Channel and BoundaryLayer Flows with a Low-Reynolds-Number Turbulence Model," AIAA Journal, January 1982, Vol. 20, No. 1, pp. 33-38.

16. Nichols, R.H., "A Two-Equation Model for Compressible Flows,” AIAA Paper 90-0494, January 1990.

17. Garrard, G., Phares, W., and Cooper, G., "Calibration of PARC for Propulsion Flows," AIAA Paper 91-2152, June 1991.

18. Seiner, J.M., and Krejsa, E.A., "Supersonic Jet Noise and the High Speed Civil Transport," AIAA Paper 892358, July 1989.

19. Stern, A., and Peracchio, A., "The Challenge of Reducing Supersonic Civil Transport Noise," AIAA Paper 892363, July 1989.

20. Tanna, H.K., "Coannular Jets - Are They Really Quiet and Why,"Journal of Sound and Vibration, 1980, Vol. 72, Part 1, pp. 97-118.

21. Tanna, H.K., Tester, B.J., and Lau, J.C., "The Noise and Flow Characteristics of Inverted Profile Coannular Jets," NASA CR-158995, 1979.
22. Von Glahn, U., Goodykoontz, J., and Wasserbauer, C., "Velocity and Temperature Decay Characteristics of Inverted-Profile Jets," AIAA Paper 86-0312, January, 1986.

23. Von Glahn, U., Goodykoontz, J., and Wasserbauer, C., "Velocity and Temperature Characteristics of TwoStream, Coplaner Jet Exhaust Plumes," AIAA Paper 842205, August 1984.

24. Heltsley, F.L., and Crosswy, F.L., "Two-Component Simultaneous LDV Turbulence Measurements in an Axisymmetric Nozzle Afterbody Subsonic Flow Fields with a Cold, Underexpanded Supersonic Jet," Arnold Engineering Development Center Report AEDC-TR-8227, June 1983.

25. Adamson, T.C., and Nicholls, J.A., "On the Structure of Jets From Highly Underexpanded Nozzles Into Still Air," Journal of the Aero/Space Sciences, January 1959.

26. Lord, W.K., Jones, C.W., Stern, A.M., Head, V.L., and Krejsa, E.A., "Mixer Ejector Nozzle for Jet Noise Suppression,” AIAA Paper 90-1909, July 1990.

27. Bevilaqua, P.M., "Advances in Ejector Thrust Augmentation,” SAE Paper 872322, 1988.

28. Bevilaqua, P.M., "Evaluation of Hypermixing for Thrust Augmenting Ejectors," Journal of Aircraft, Vol. 11, No. 6, June 1974, pp. 348-354.

29. McFarlan, J.D., McMurry, C.B., and Scaggs, W.F., "Computational Investigation of Two-Dimensional Ejector Nozzle Flowfields," AIAA Paper 90-2148, July 1990.

30. Gilbert, G.B., and Hill, P.G., "Analysis and Testing of Two-Dimensional Slot Nozzle Ejectors With Variable Area Mixing Sections," NASA CR-2251, 1973. 


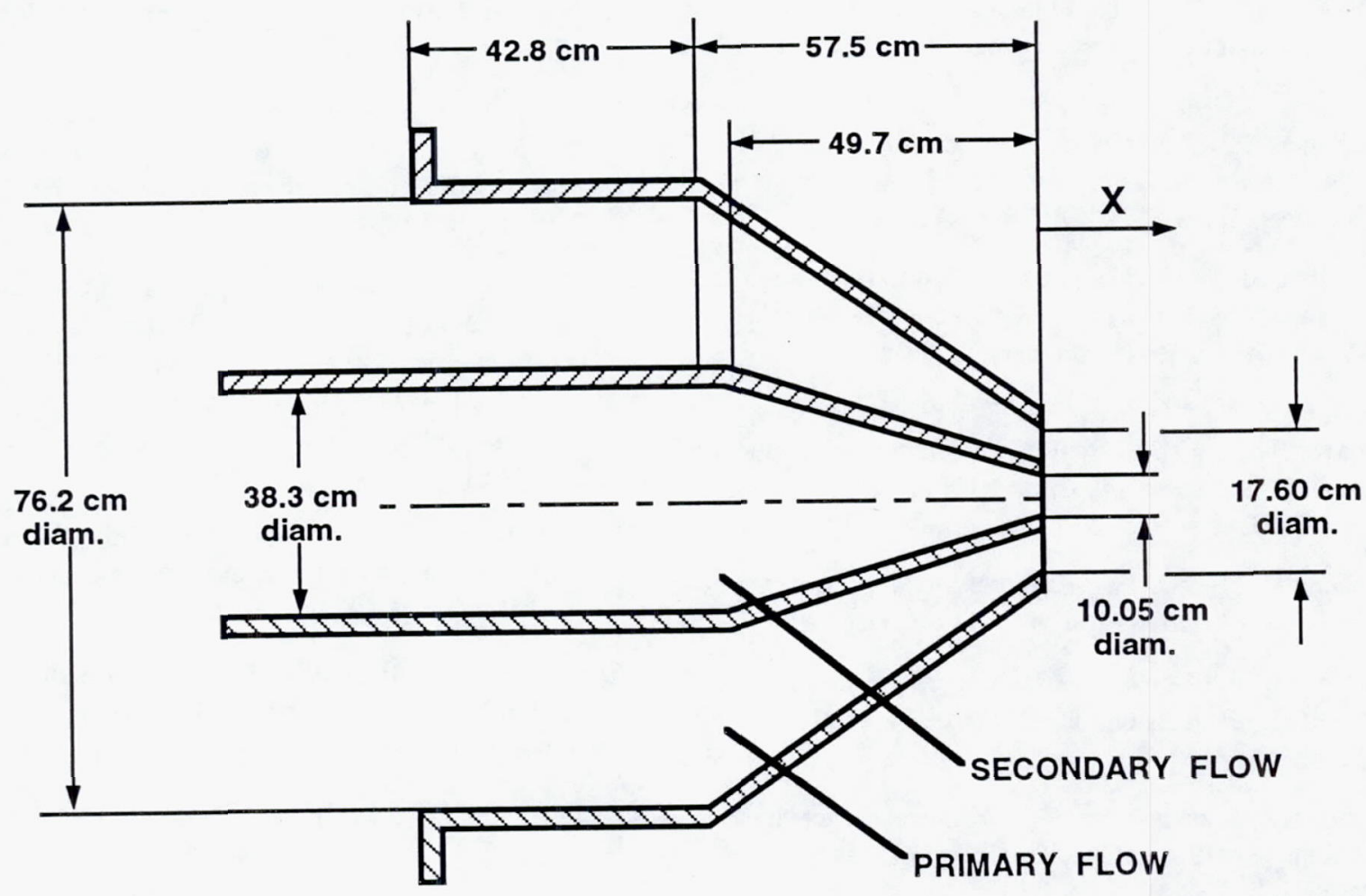

Figure 1. Schematic of Inverted Velocity Profile Nozzle.
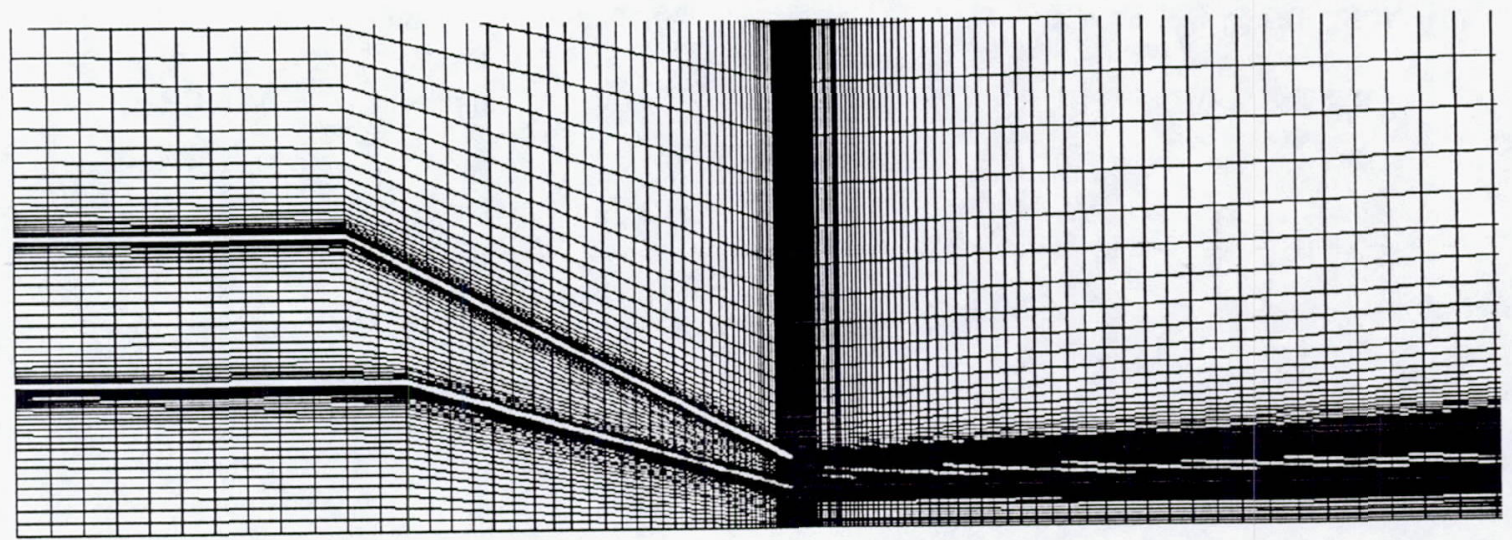

Figure 2. Grid detail near inverted velocity profile nozzle exit plane. 


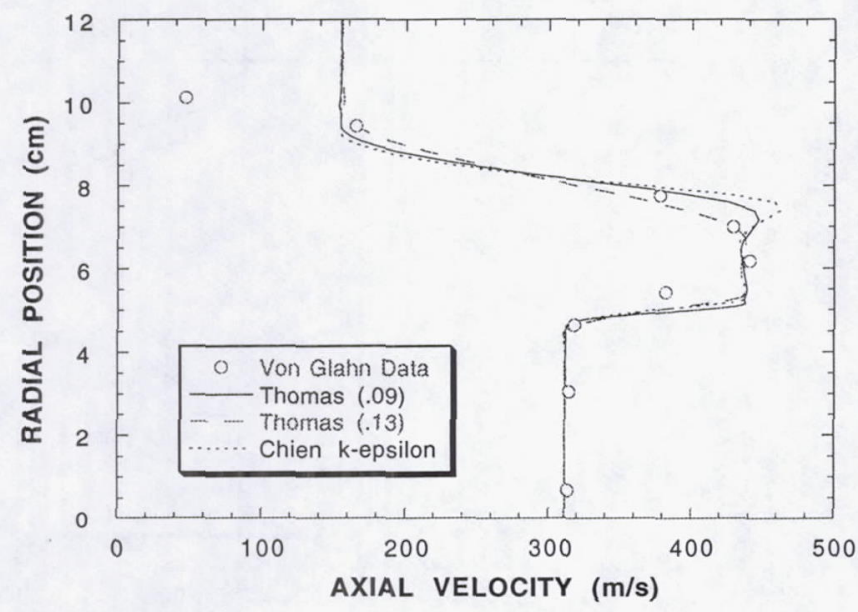

(a) $x=20 \mathrm{~cm}$

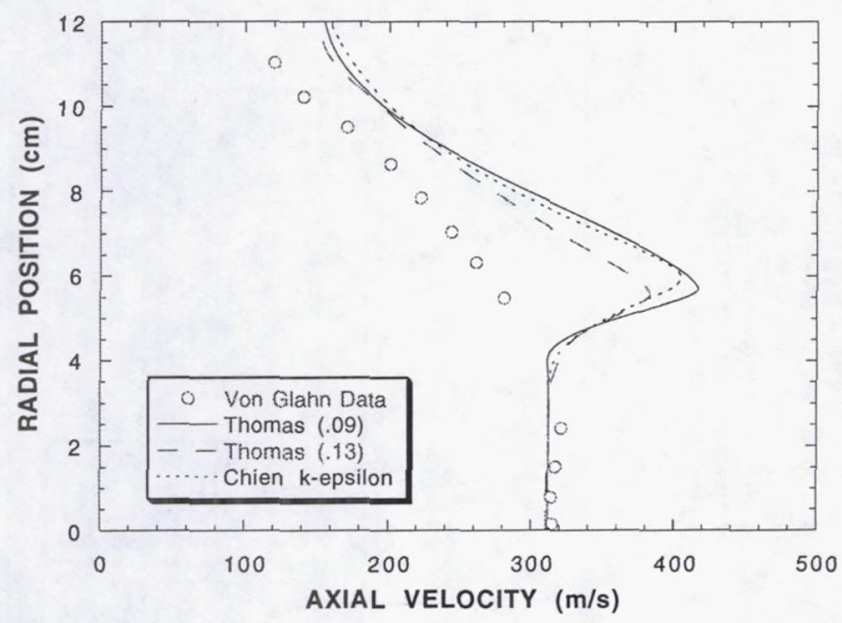

(c) $x=81 \mathrm{~cm}$

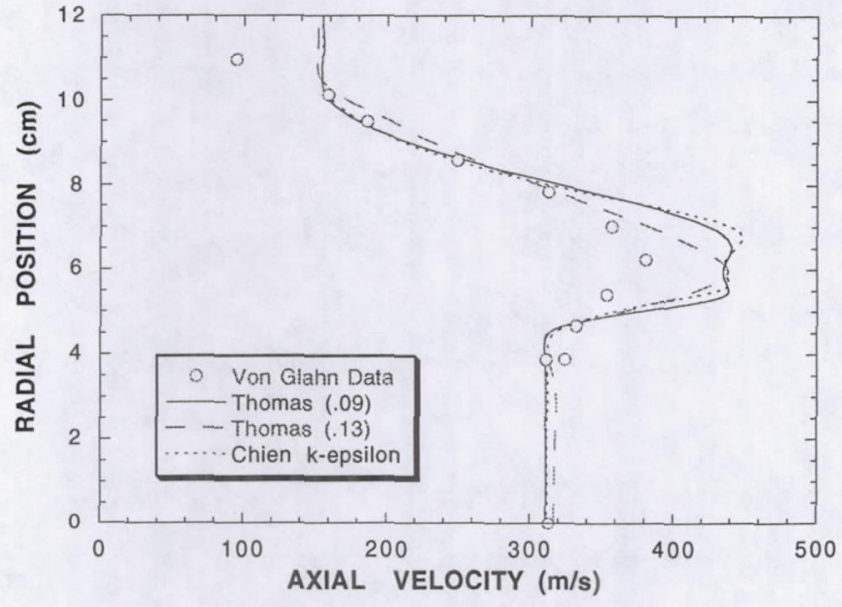

(b) $x=40 \mathrm{~cm}$

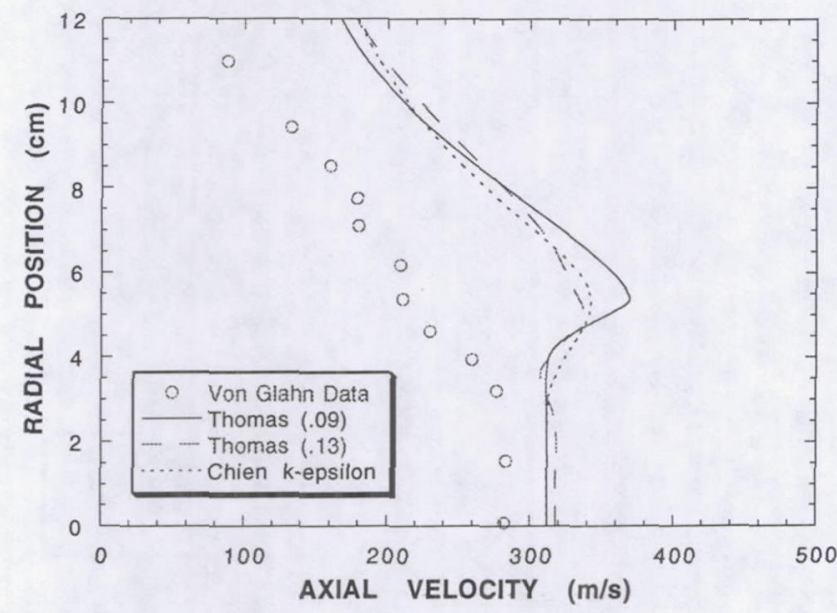

(d) $x=130 \mathrm{~cm}$

Figure 3. Velocity profiles for IVP nozzle. 


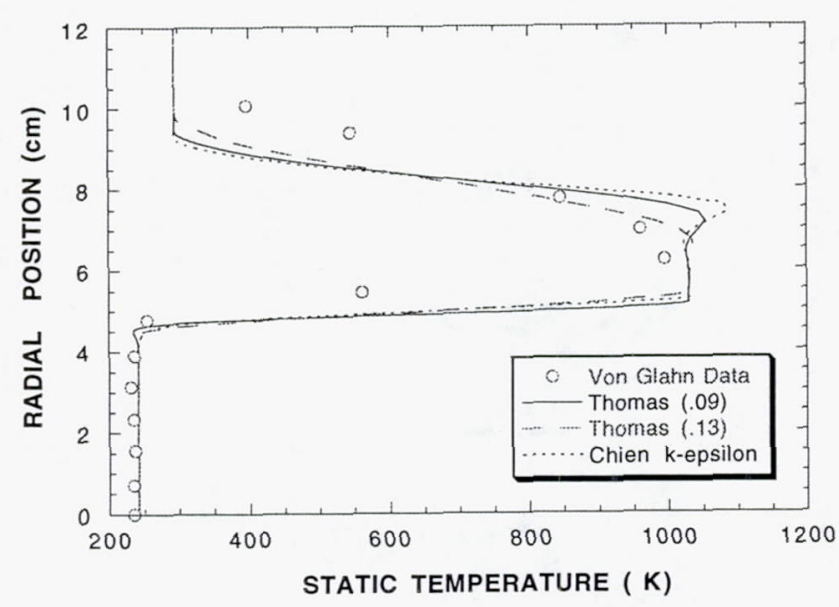

(a) $x=20 \mathrm{~cm}$

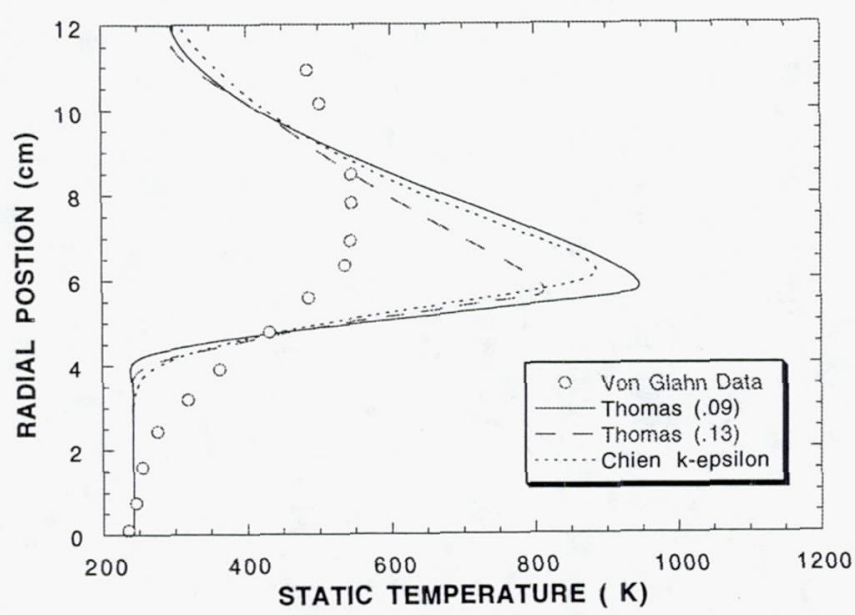

(c) $x=81 \mathrm{~cm}$

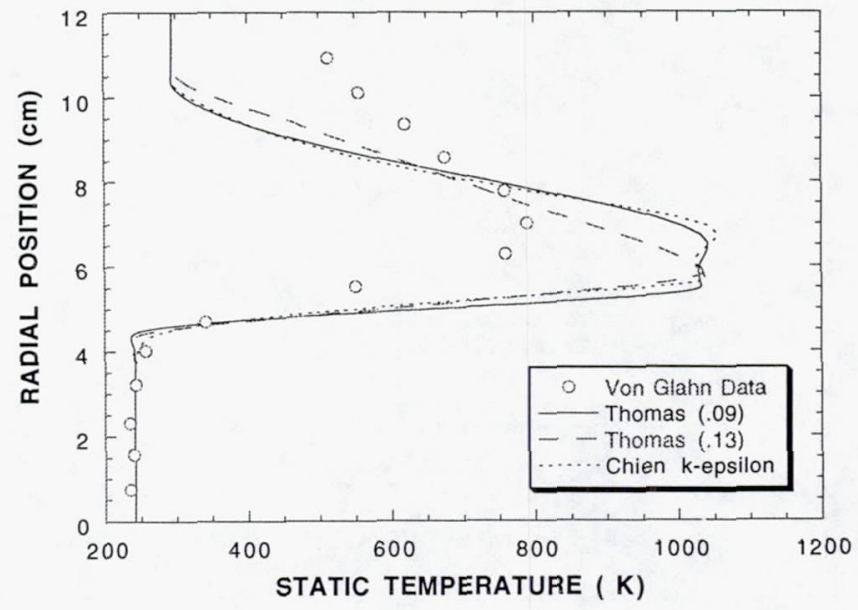

(b) $x=40 \mathrm{~cm}$

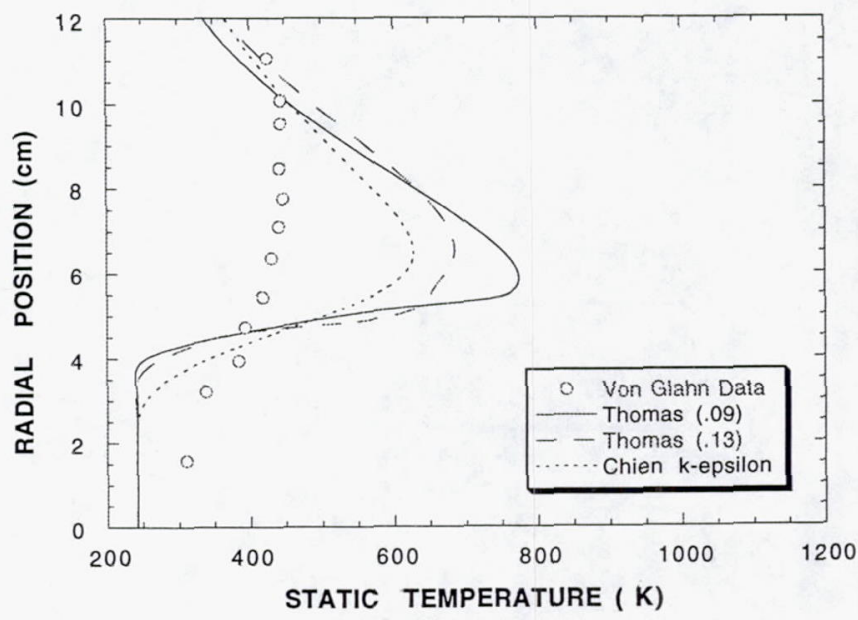

(d) $x=130 \mathrm{~cm}$

Figure 4. Temperature profiles for IVP nozzle. 

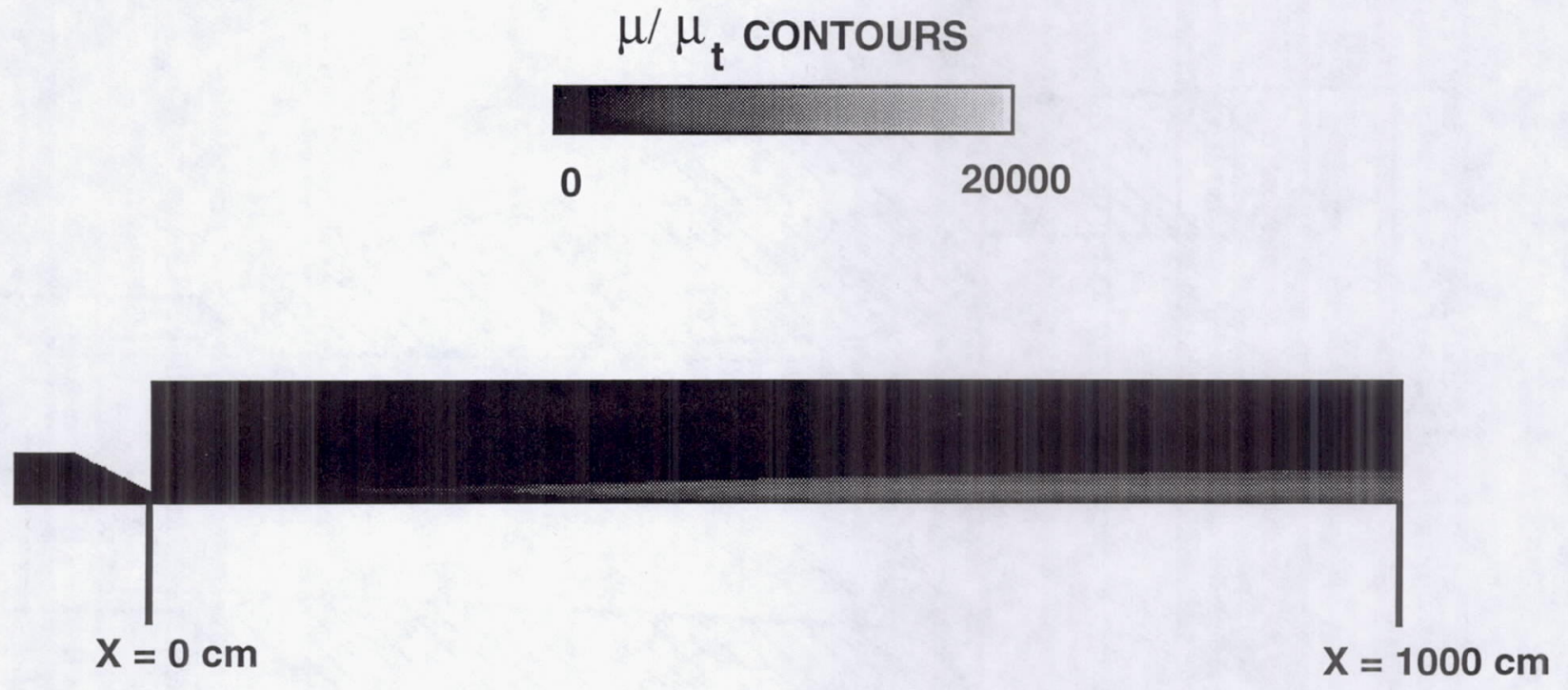

(a) Thomas (COFMIX $=0.09$ )

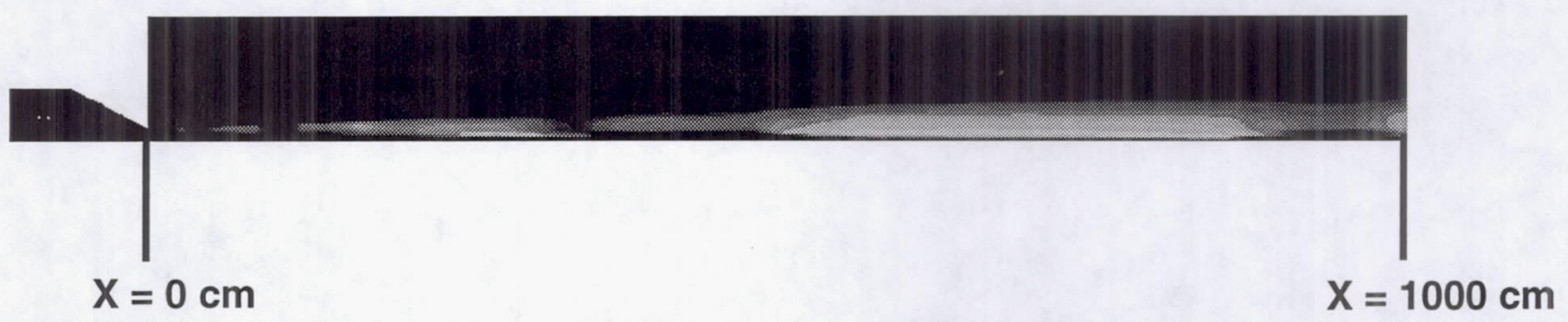

(b) Thomas (COFMIX $=0.13$ )

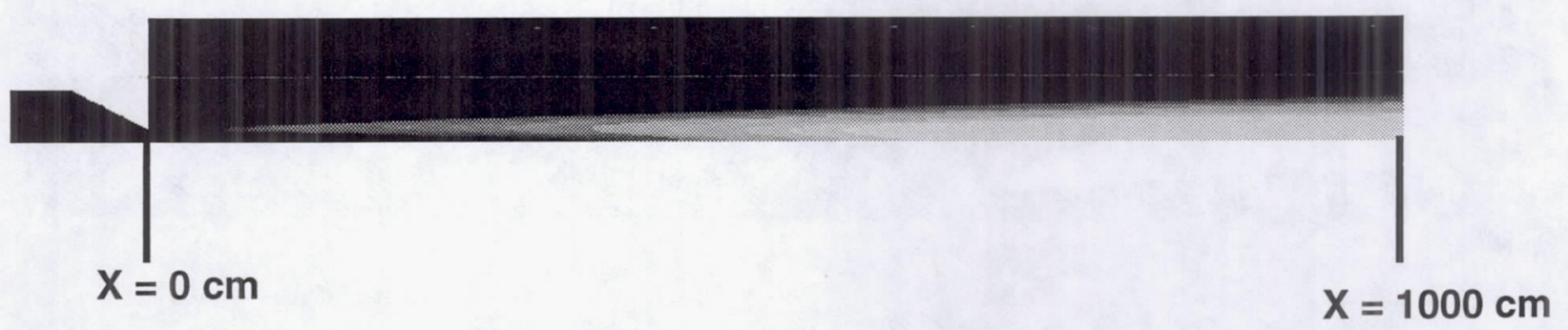

(c) Chien k- $\varepsilon$

Figure 5. Turbulent viscosity contours for inverted velocity profile nozzle. 


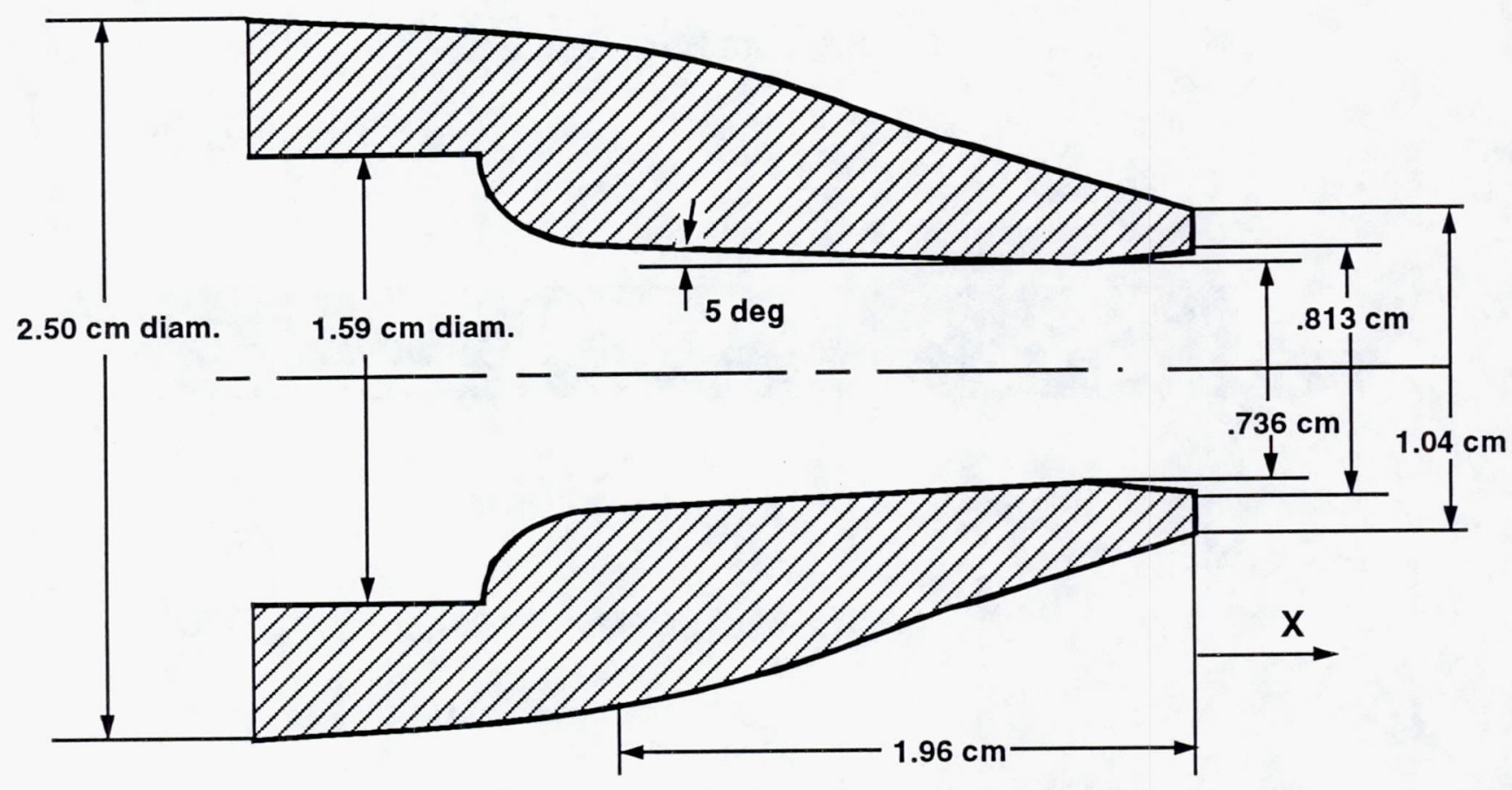

Figure 6. Schematic of underexpanded nozzle.

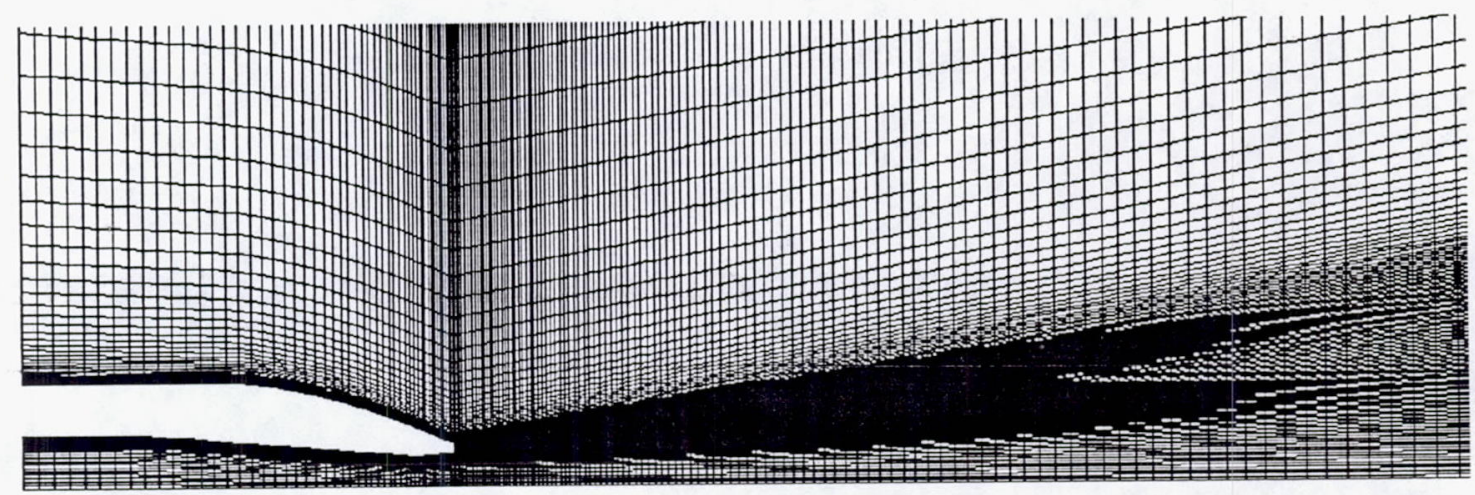

Figure 7. Grid detail near underexpanded nozzle exit plane. 


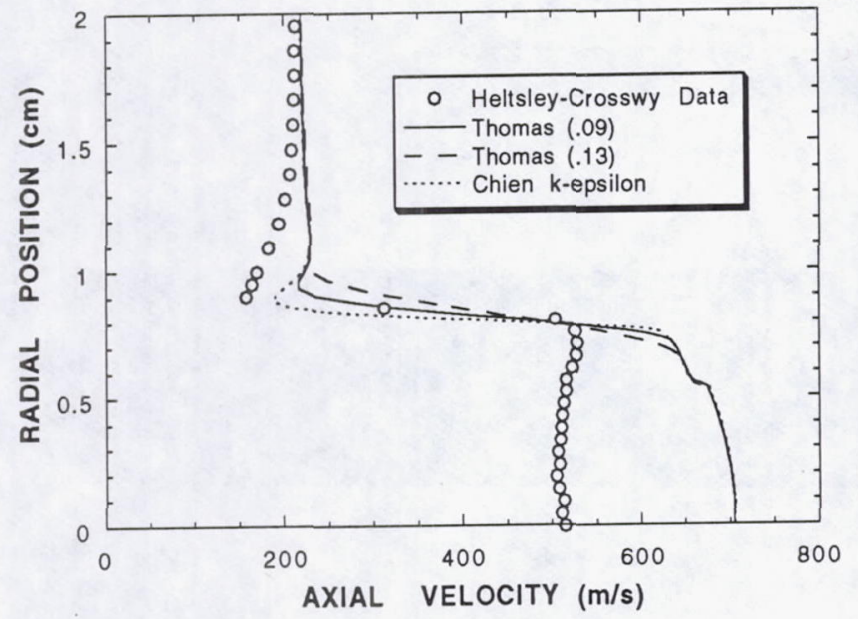

(a) $x=1.27 \mathrm{~cm}$

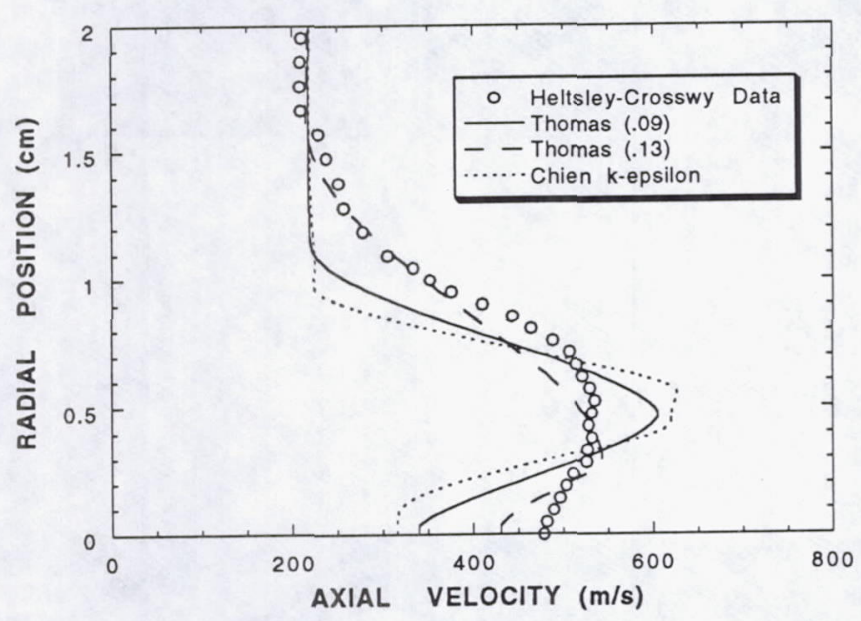

(c) $x=6.35 \mathrm{~cm}$

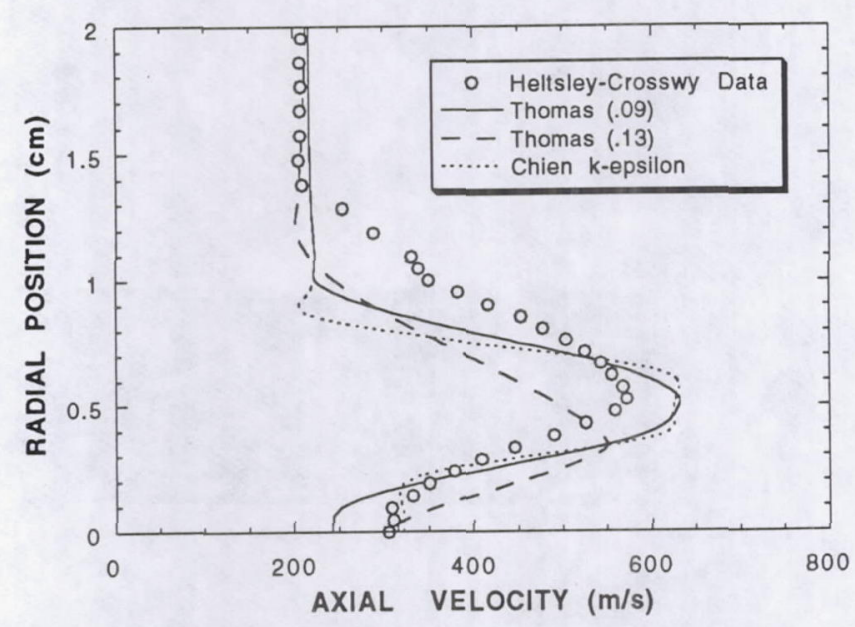

(b) $x=3.80 \mathrm{~cm}$

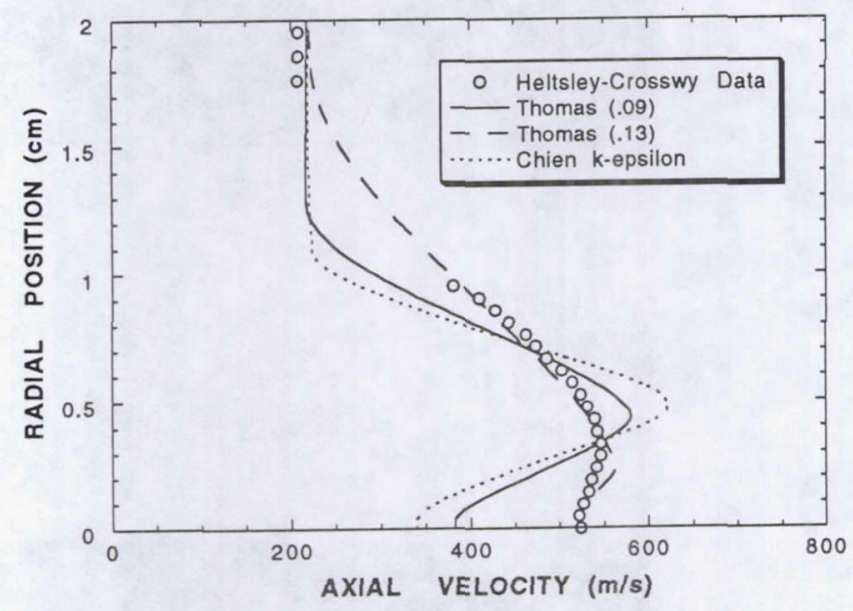

(d) $x=8.90 \mathrm{~cm}$

Figure 8. Velocity profiles for underexpanded nozzle. 

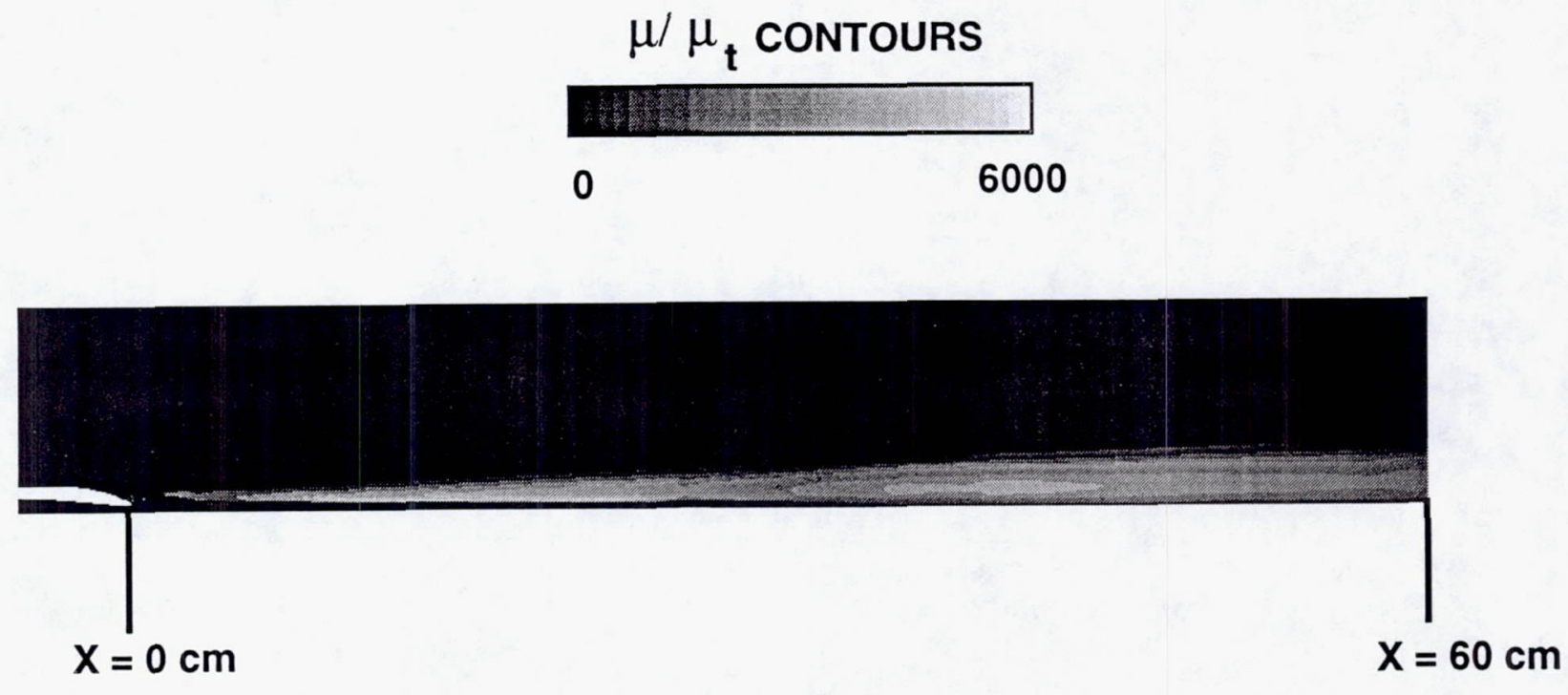

(a) Thomas (COFMIX $=0.09$ )

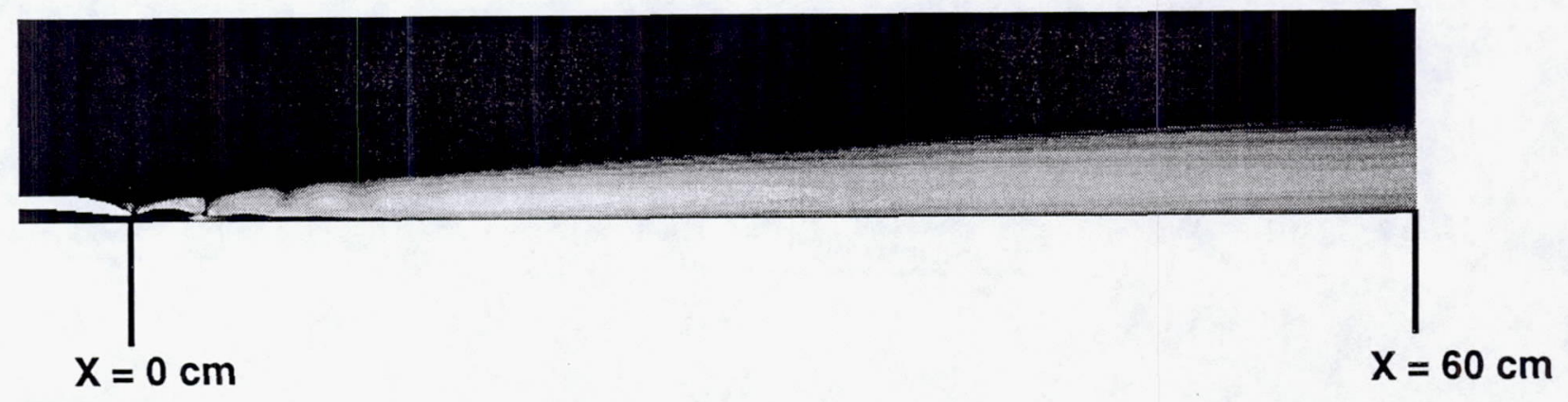

(b) Thomas (COFMIX $=0.13$ )

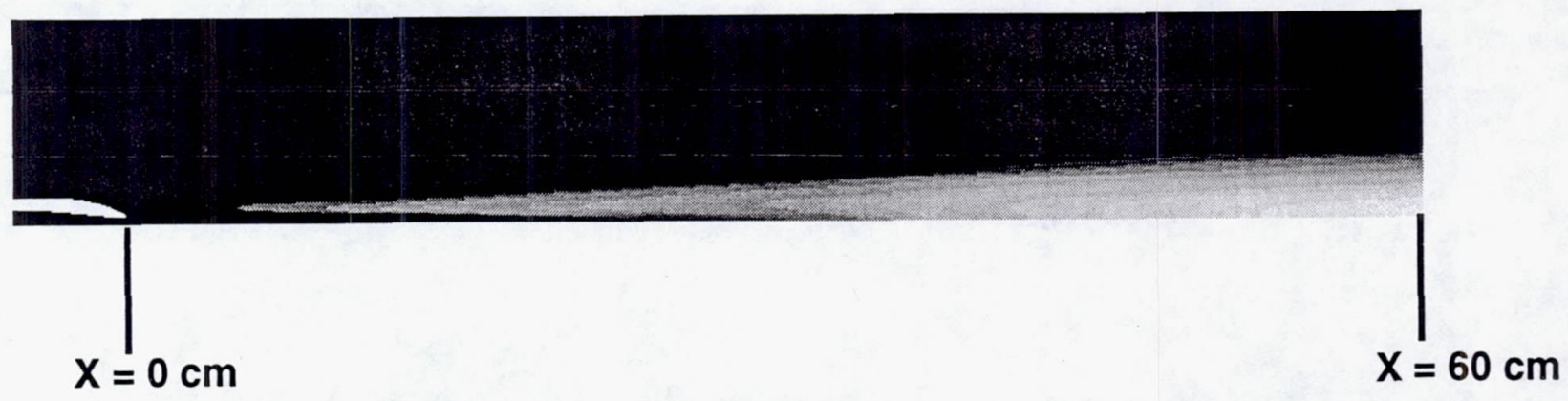

(c) Chien k- $\varepsilon$

Figure 9. Turbulent viscosity contours for underexpanded nozzle. 


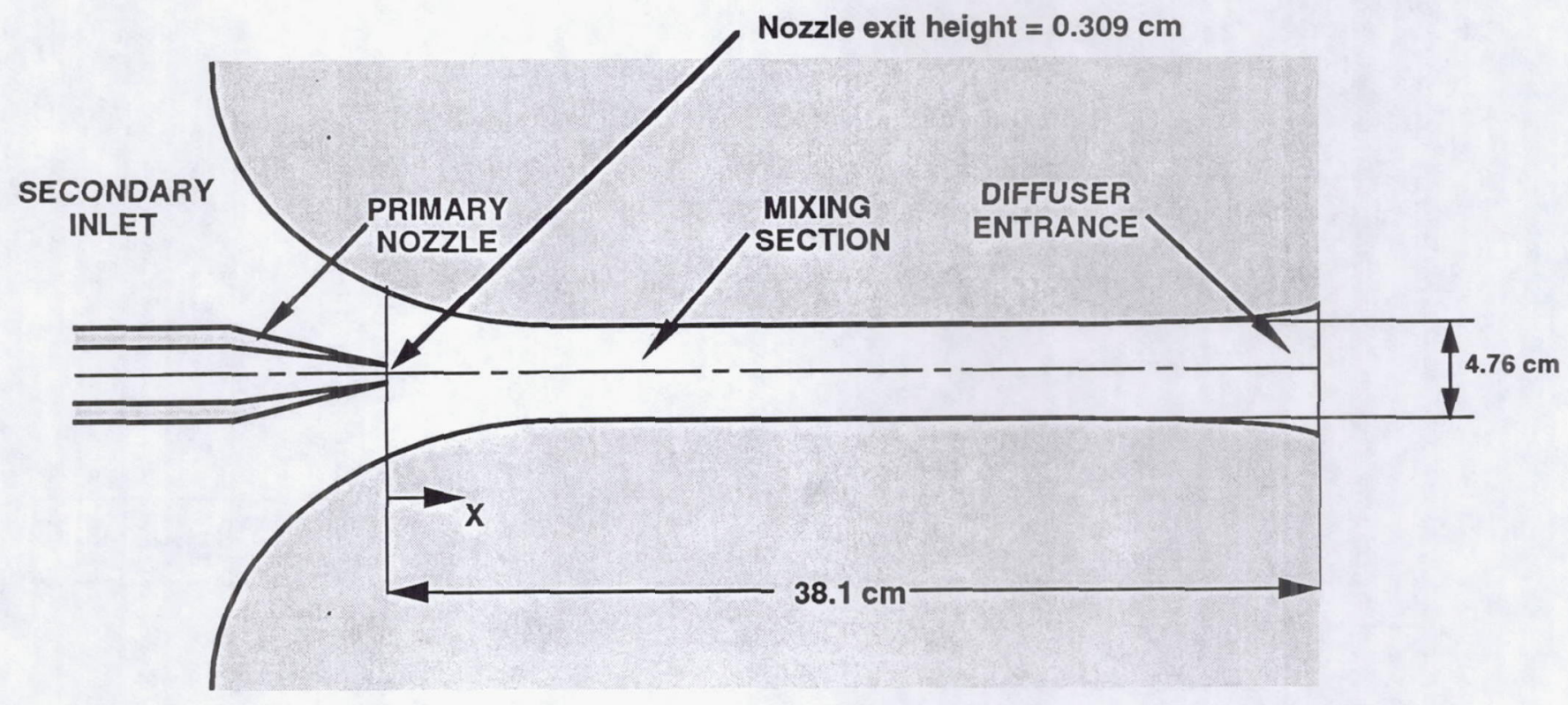

Figure 10. Schematic of 2D ejector nozzle.

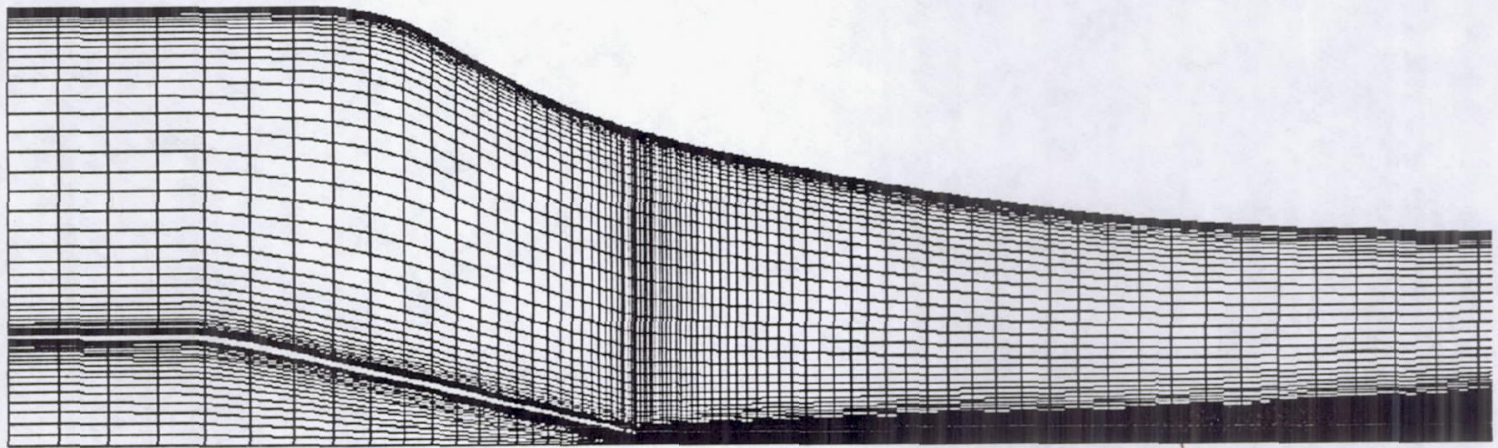

Figure 11. Grid detail near 2D ejector nozzle exit plane. 


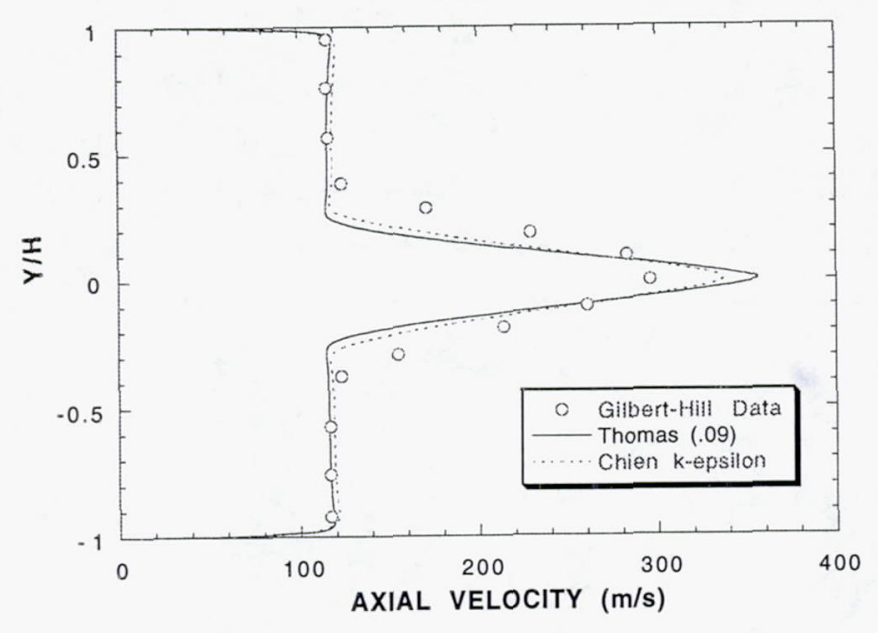

(a) $x=7.6 \mathrm{~cm}$

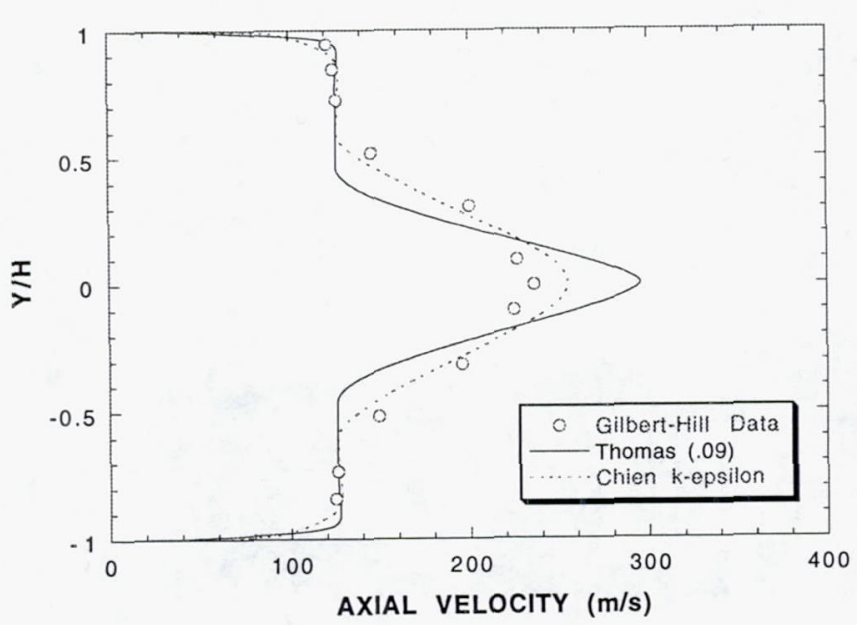

(c) $x=17.8 \mathrm{~cm}$

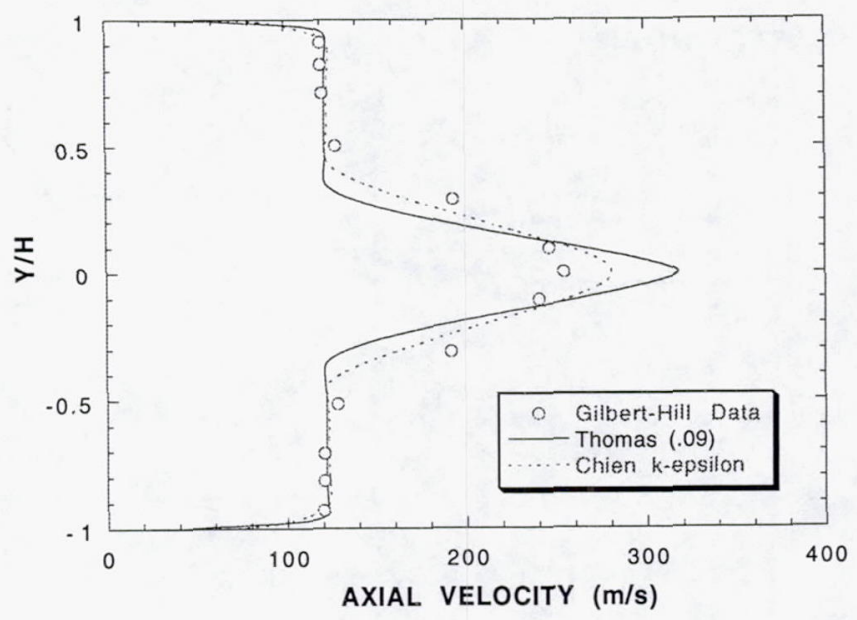

(b) $x=12.7 \mathrm{~cm}$

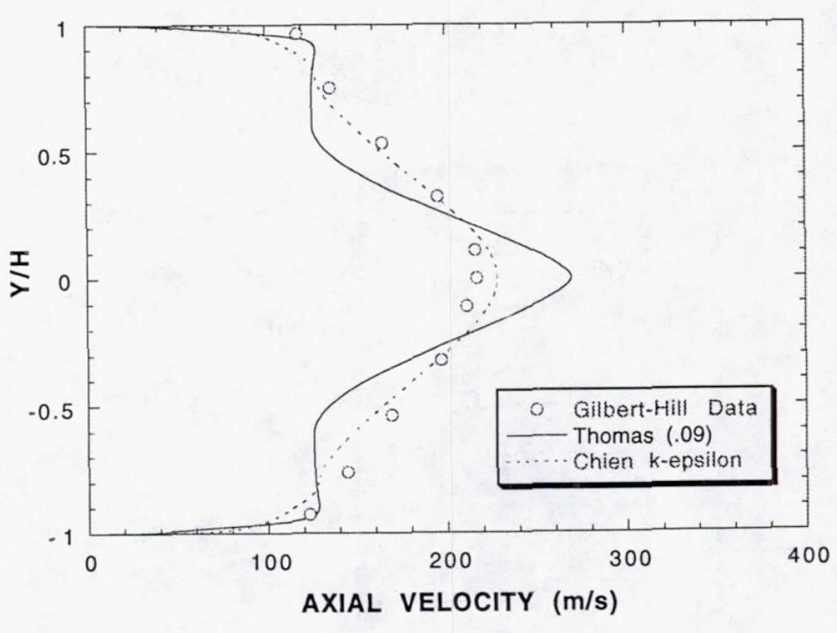

(d) $x=26.7 \mathrm{~cm}$

Figure 12. Velocity profiles for 2D ejector nozzle. 


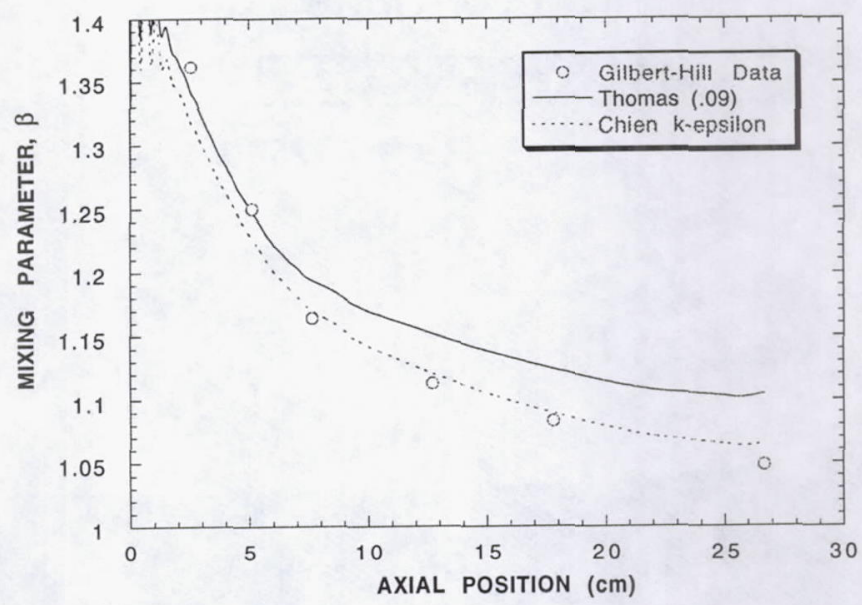

Figure 13. Mixing effectiveness for 2D ejector nozzle.

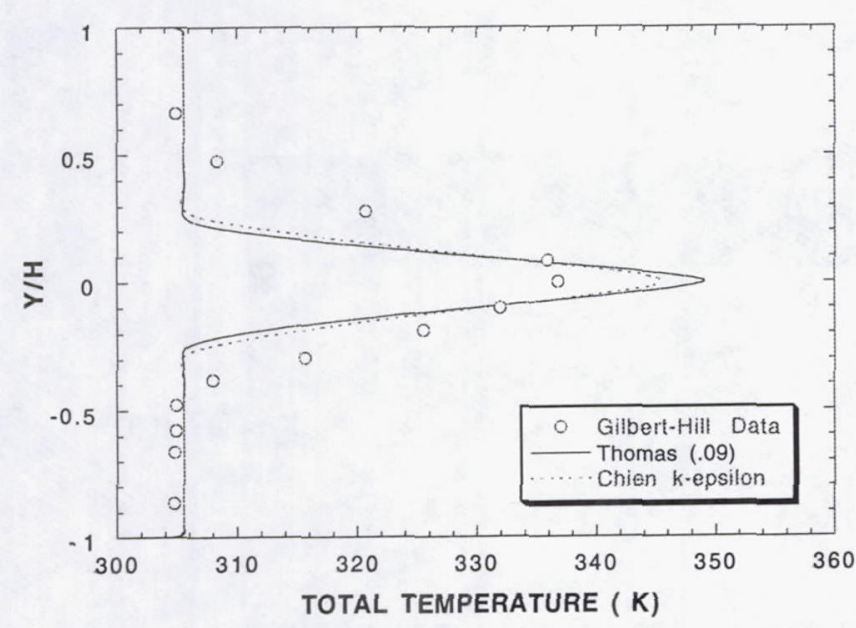

(c) $x=7.6 \mathrm{~cm}$

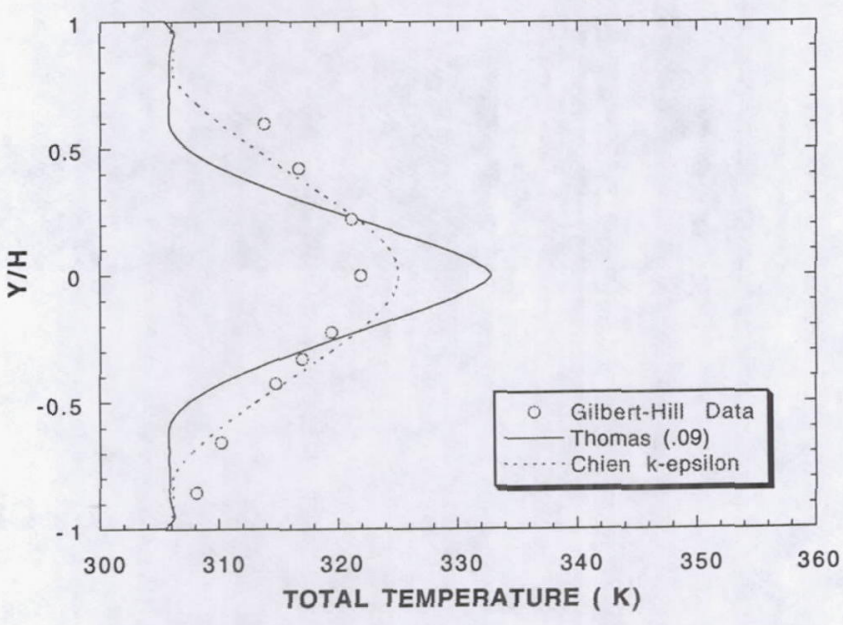

(d) $x=26.7 \mathrm{~cm}$

Figure 14. Total temperature profiles for 2D ejector nozzle. 


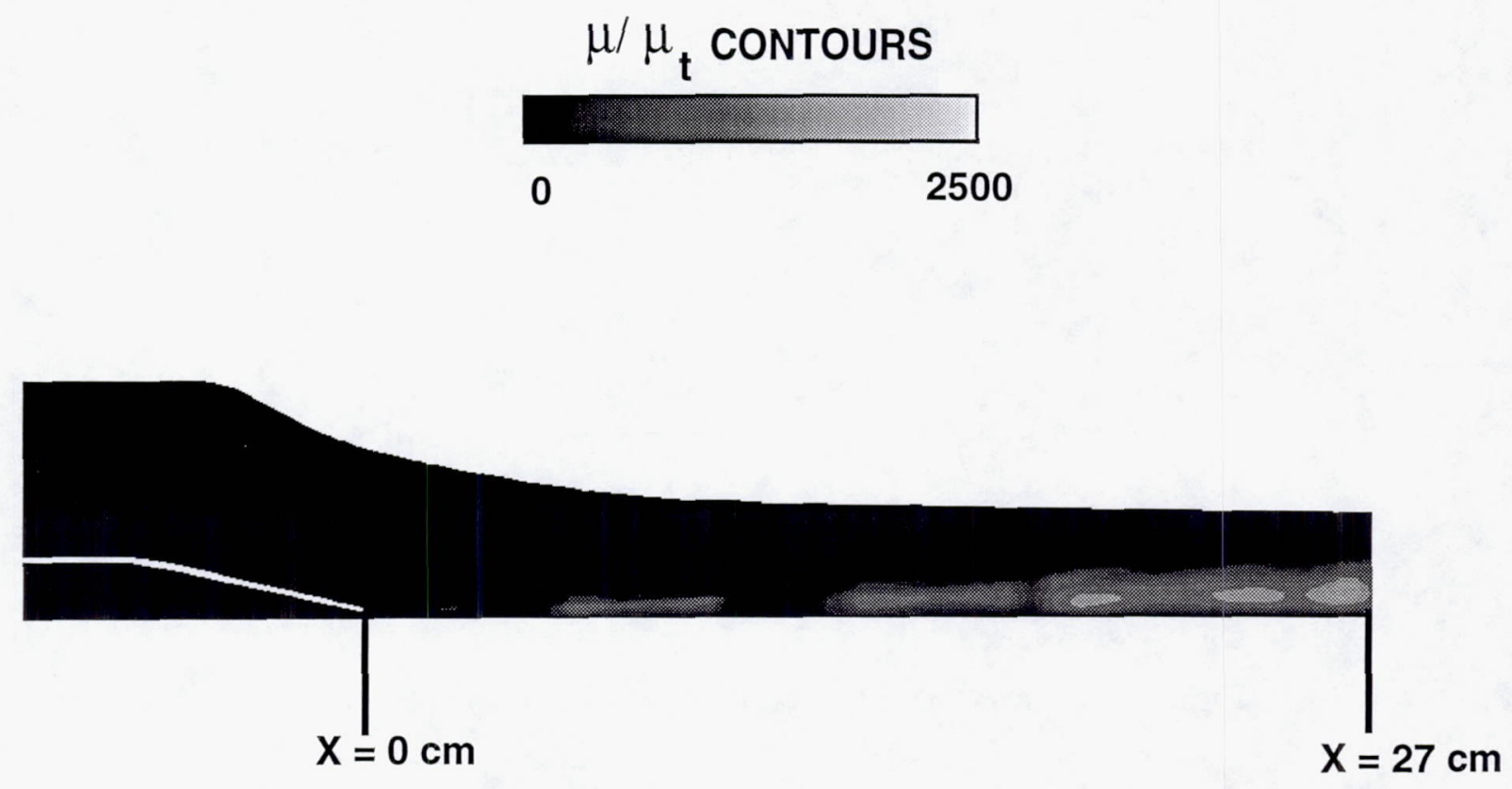

(a) Thomas (COFMIX $=0.09$ )

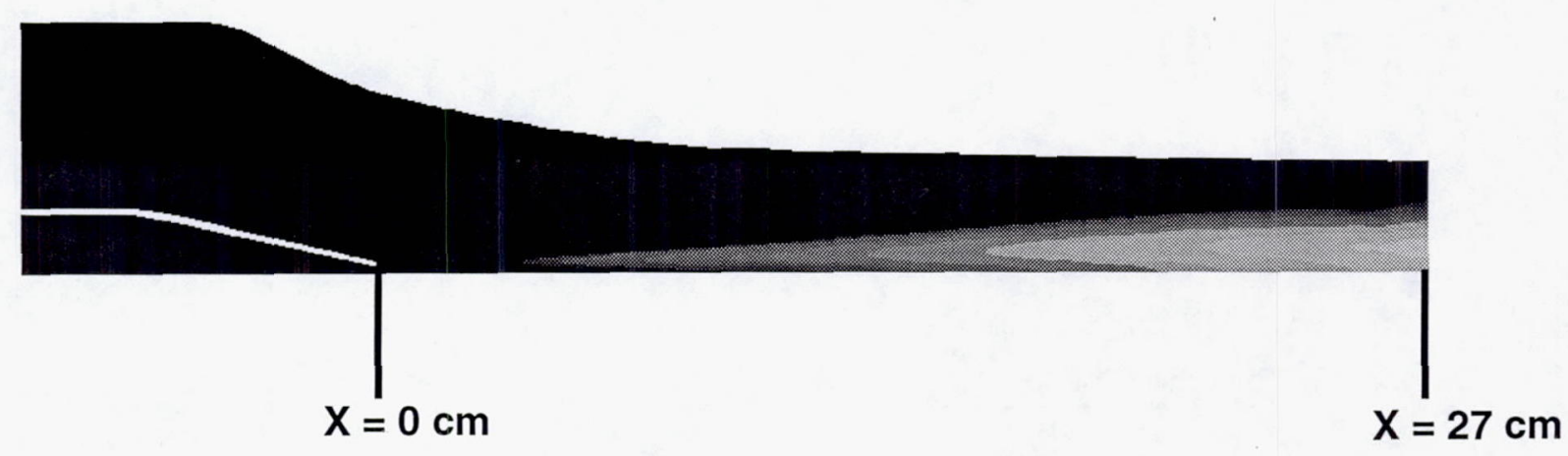

(b) Chien k- $\varepsilon$

Figure 15. Turbulent viscosity contours for 2D ejector nozzle. 
Public reporting burden for this collection of information is estimated to average 1 hour per response, including the time for reviewing instructions, searching existing data sources, gathering and maintaining the data needed, and completing and reviewing the collection of information. Send comments regarding in

gathering and maintaining the dation of information, including suggestions for reducing this burden, to Washington Headquarters Services, Directorate for Information Operations and Reports, 1215 Je
collection

\begin{tabular}{|l|c|r|}
\hline 1. AGENCY USE ONLY (Leave blank) & 2. REPORT DATE & 3. REPORT TYPE AND DATES COVERED \\
June 1994 & Technical Memorandum
\end{tabular}

4. TITLE AND SUBTITLE

5. FUNDING NUMBERS

Use of Navier-Stokes Methods for the Calculation of High-Speed

Nozzle Flow Fields

6. AUTHOR(S)

WU-537-02-23

Nicholas J. Georgiadis and Dennis A. Yoder

7. PERFORMING ORGANIZATION NAME(S) AND ADDRESS(ES)

National Aeronautics and Space Administration

Lewis Research Center

Cleveland, Ohio 44135-3191

8. PERFORMING ORGANIZATION REPORT NUMBER

E-8703

9. SPONSORING/MONITORING AGENCY NAME(S) AND ADDRESS(ES)

10. SPONSORING/MONITORING AGENCY REPORT NUMBER

National Aeronautics and Space Administration

Washington, D.C. 20546-0001

NASA TM-106551

AIAA-94-3212

\section{SUPPLEMENTARY NOTES}

Prepared for the 30th Joint Propulsion Conference, cosponsored by the AIAA, ASME, SAE, and ASEE, Indianapolis, Indiana, June 27-29, 1994. Responsible person, Nicholas J. Georgiadis, organization code 2740, (216) 433-3958.

12a. DISTRIBUTION/AVAILABILITY STATEMENT

12b. DISTRIBUTION CODE

Unclassified - Unlimited

Subject Category 02

\section{ABSTRACT (Maximum 200 words)}

Flows through three reference nozzles have been calculated to determine the capabilities and limitations of the widely used Navier-Stokes solver, PARC. The nozzles examined have similar dominant flow characteristics as those considered for supersonic transport programs. Flows from an inverted velocity profile (IVP) nozzle, an underexpanded nozzle, and an ejector nozzle were examined. PARC calculations were obtained with its standard algebraic turbulence model, Thomas, and the two-equation turbulence model, Chien k- $\epsilon$. The Thomas model was run with the default coefficient of mixing set at both 0.09 and a larger value of 0.13 to improve the mixing prediction. Calculations using the default value substantially underpredicted the mixing for all three flows. The calculations obtained with the higher mixing coefficient better predicted mixing in the IVP and underexpanded nozzle flows but adversely affected PARC's convergence characteristics for the IVP nozzle case. The ejector nozzle case did not converge with the Thomas model and the higher mixing coefficient. The Chien $\mathrm{k}-\epsilon$ results were in better agreement with the experimental data overall than were those of the Thomas run with the default mixing coefficient, but the default boundary conditions for $\mathrm{k}$ and $\epsilon$ underestimated the levels of mixing near the nozzle exits.

\section{SUBJECT TERMS}

Nozzle; Navier-Stokes; Turbulence model; Mixing; Ejector; Supersonic transport

17. SECURITY CLASSIFICATION OF REPORT

Unclassified
18. SECURITY CLASSIFICATION OF THIS PAGE

Unclassified
19. SECURITY CLASSIFICATION OF ABSTRACT Unclassified
15. NUMBER OF PAGES

20

16. PRICE CODE

$\mathrm{A} 03$

20. LIMITATION OF ABSTRACT 